أحكام المماية الجنائية للجنين بين الشريعة و القانون

$$
\text { بخدة صفُبان }
$$

كلية الحقوق والعلوم السياسية الجامعة دكتور مولاي الطاهر -

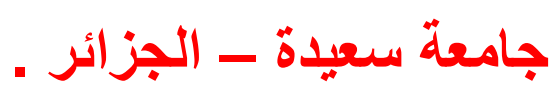


أحكام الحماية الجنائية للجنين بين الثريعة والقانون

- $0 \vee 7$. 
مجلة كلية الثريعة والقانون بتفهنا الأثراف ـ دقهلية العدد الثالث والعشرون لسنة اب ـ بم الجزء الأول

أحكام الحماية الجنائية للجنين بين الشريعة و القانون

بخدة صفيان .

قسم الحقوق ، كلية الحقوق و العلوم السياسية الجامعة دكتور مولاي الطاهر ، المدينة سعيدة ، الدولة الجزائر . - مائ.

Sofiane.bekhedda@univ-saida.dz البريد الاككتروني المهني:

ملخص البحث::

يعد الطفل الثمرة المرجوة من العلاقة الزوجية بل يعتبر من أهم مقاصده فهو الهبة الكبيرة التي وهبها الله للإنسان في حياته من اجل العناية به والإحسان إليه ويقع على عاتق الأسرة والمجتمع، ولا تعتبر ولادة الطفل بداية حياته بل انه يمر بعدة مر احل في بطن أمه قبل ان يصبح طفلا، والمرحلة المهمة التي يمر بها قبل الولادة هي مرحلة توطين الجنين وتحديد معالمه الوراثية ذكرا كان أو أنثى، وقد بينت الثريعة الإسلامية مر احل نموه لحين و لادته

، وبينت الحقوق التي بتمتع بها وحردت اي اعتداء عليها بغية المحافظة على الطفل لأنه أساس التكوين البشري وكل ما يمس المجتمع ، اما التشريعات والقوانين الوضعية فقد ضمت قو اعد وضو ابط تحفظ حقوقه وتجرم الاعتداء عليه. الكلمات المفتاحية : الجنين ، الثرع ، القانون ، الحماية الجنائية ، حقوق ، الاجهاض. 
Criminal provisions for the fetus between Sharia and the law

\section{BEKHEDDA SOFIANE}

DEPARTMENT OF Law , FACULTY OF Law and Political Science

UNIVERSITY of Dr. Moulay El-Taher, CITY SAIDA, COUNTRY Algeria .

E-mail : sofiane.bekhedda@univ-saida.dz

\section{ABSTRACT:}

The child is the desired fruit of the marital relationship, but it is considered one of the most important of his purposes, as it is the great gift that God gave to man in his life in order to take care of him and be kind to him and it is the responsibility of the family and society. A child, and the important stage that he goes through before birth is the stage of settling the fetus and determining its genetic features, whether male or female, and Islamic law has shown the stages of its development until its birth

And it indicated the rights that he enjoys and prohibited any abuse thereof in order to protect the child, because it is the basis of human formation and everything that affects society. As for the laws and man-made laws, they included rules and controls that preserve his rights and criminalize the abuse of him.

KEYWORDS: The fetus, Sharia, Law, Criminal Protection , Rights, Miscarriage. 
مجلة كلية الثريعة والقانون بتفهنا الأثراف ـ دقهلية العدد الثالث والعشرون لسنة اب ـ بم الجزء الأول

\section{مقدمة}

عرفت العهود الأولى للبشرية الإباحية المطلقة، فيما يخص إنهاء الحمل قبل الأوان و الأبه

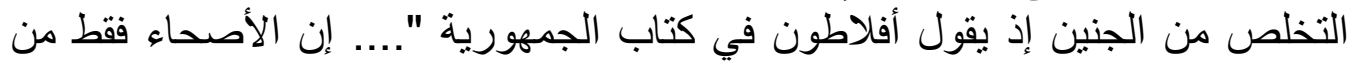

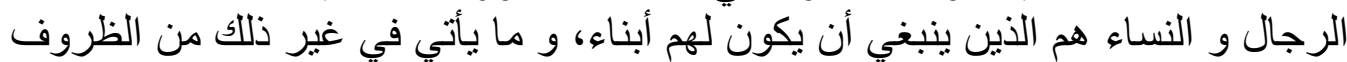

$$
\text { ينبغي التخلص منه". }
$$

ولكن عكس ذللك فقد اهتمت كل الثرائع السماوية و القوانين الوضعية المختلفة بشؤون

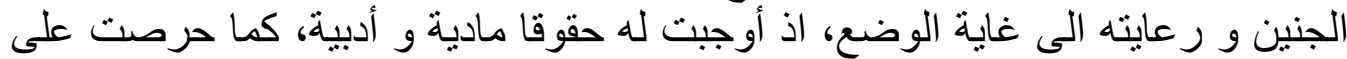

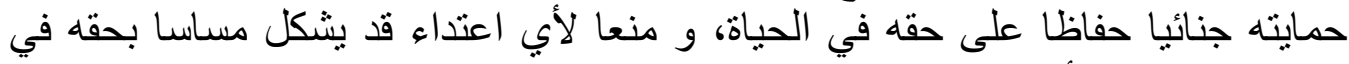

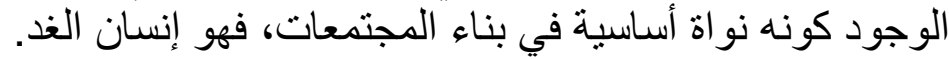
وتعتبر الثريعة الإسلامية أحسن مثال لحماية الجنين حيث نص القران الكريم على

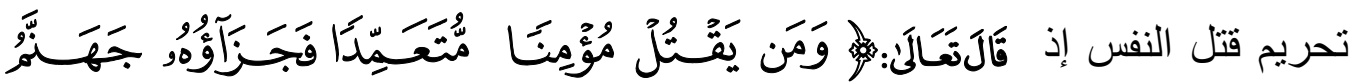

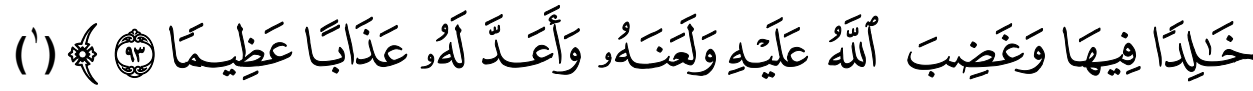

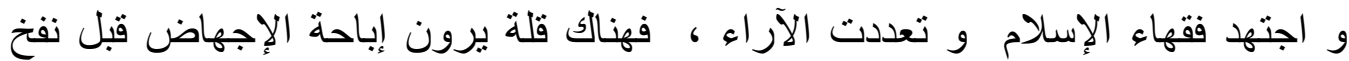

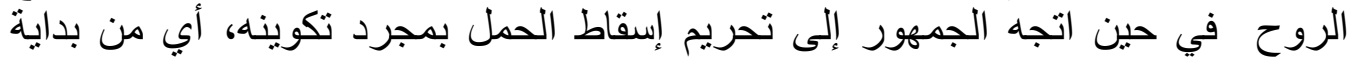
التلقيح، و حرموا الاعتداء على الجنين بكافة صوره ما عدا الضرورة منها.

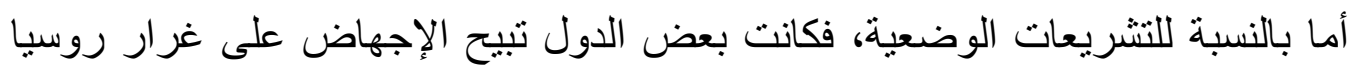

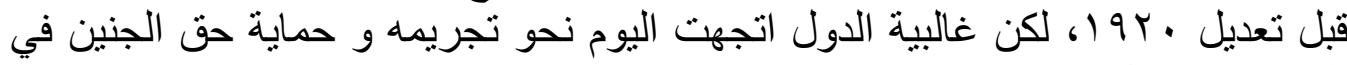

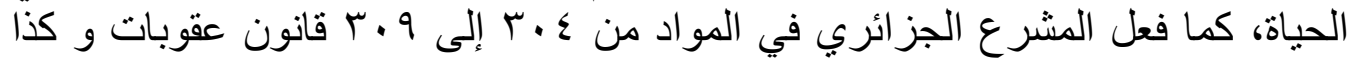

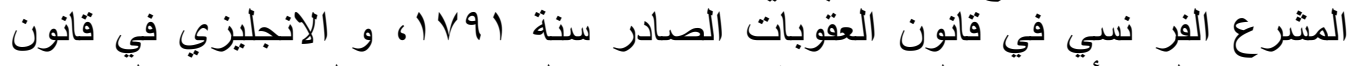

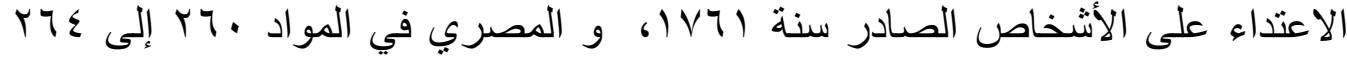

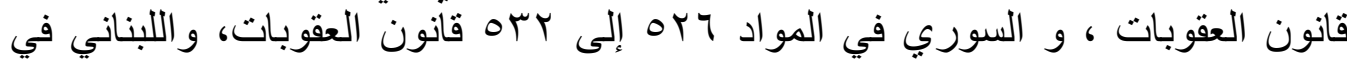

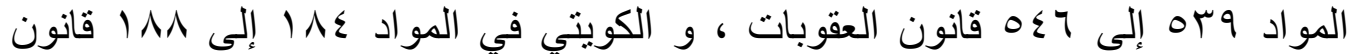

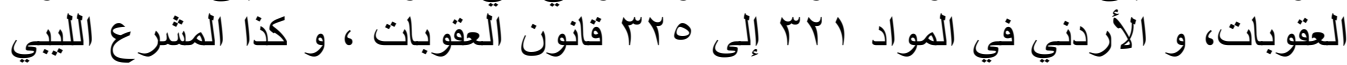

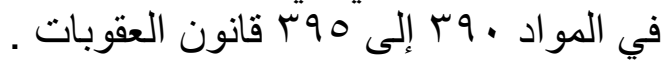
يكتسي هذا الموضوع أهمية بالغة حيث تناولته كل الثرائع السماوية بما فيها الثريعة

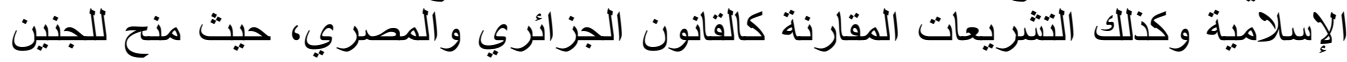
الحق في استمر ار حياته و اكتمال نموهو و تطوره داخل الرنات الرحم . 
وبالتالي أصبح هذا الموضوع يمس كيان المجتمعات، مما دعانا لدراسة الحمل باعتباره

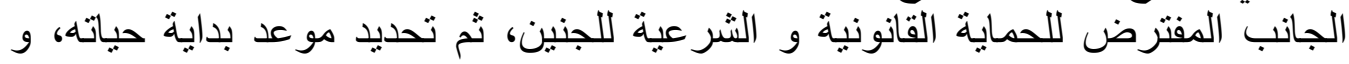

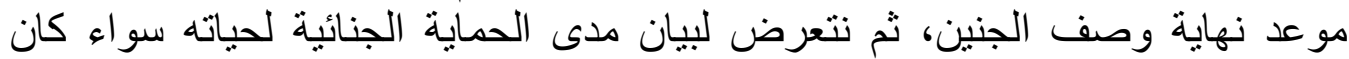
داخل الرحم أو خارجه كما هو الحال بالنسبة للبويضات الملقيحة في أنابيب. و على هذا الأساس يمكن طرح الإشكالية التالية

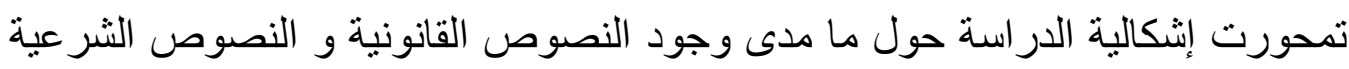
المكرسة لحماية الجنين؟

وما مدى ملائمة هذه القوانين مع تطور عصر التكنولوجيا؟ الذي ازداد معه انتهاكات

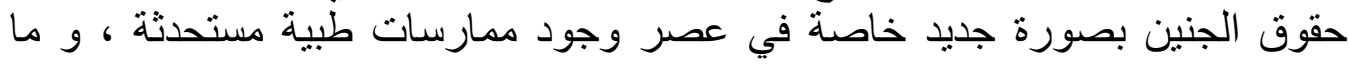
مدى فعالية هذه القو انين في تحقيق حمانية فعالة للجنين ؟

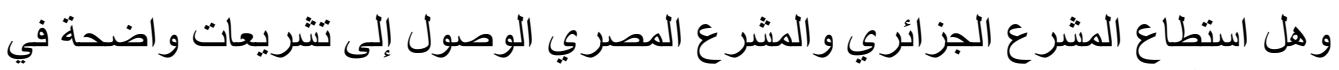

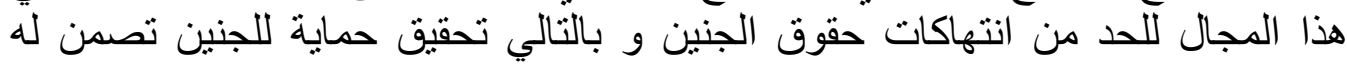

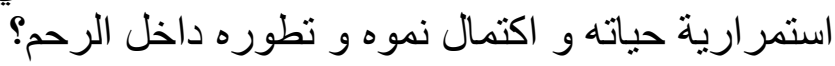

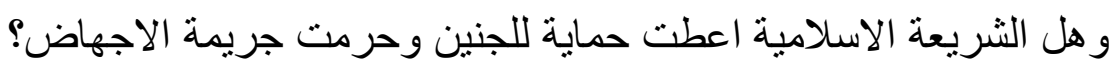
و هل هنالك إجهاض مرخص به في الثريعة الإسلامية وفي القانون الوضعي ؟

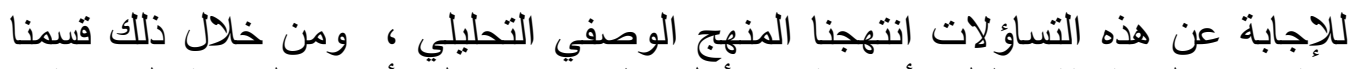

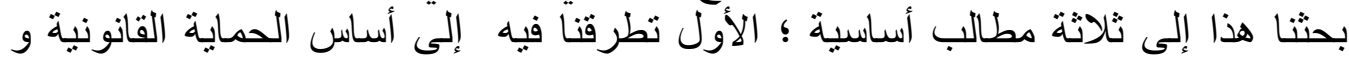

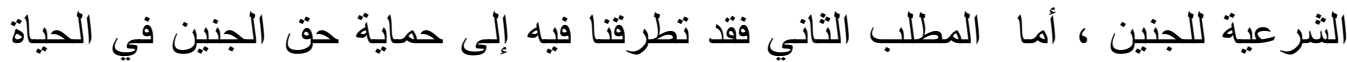

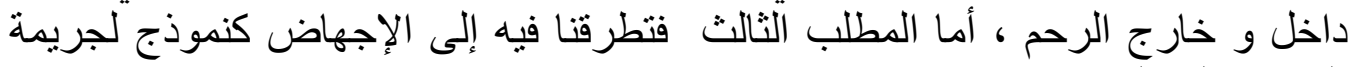

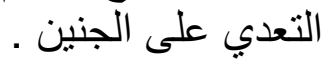


مجلة كلية الثريعة والقانون بتفهنا الأثراف ـ دقهلية العدد الثالث والعشرون لسنة اب ـ بم الجزء الأول

\section{المطلب الأول}

\section{أساسر العماية القانونبية و الشر عية اللجنبزن}

\section{أولا: تحديد موعد بلاية حياة الجنين / التعريف الجنين:}

يجمع فقهاء القانون و علماء الطب على أن الجنين هو المادة التي تتكون في الرحم من التصني

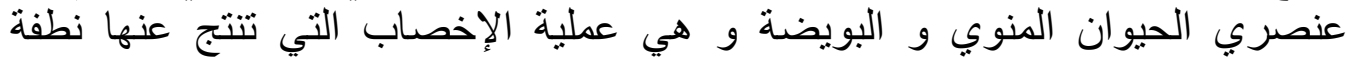

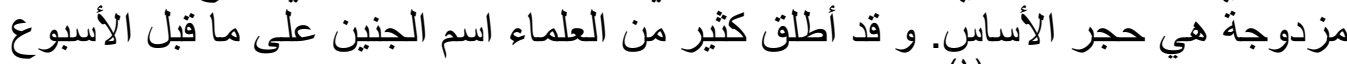

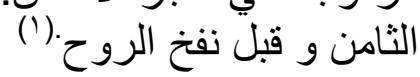
و يرى فقهاء الثريعة الإسلامية أن الجنين اسم للولد في البطن؛ فالجنين من الأجنان و

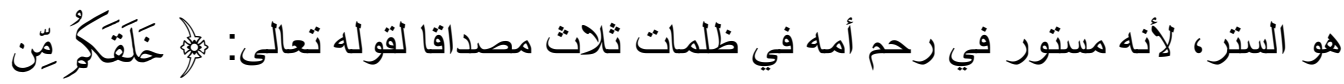

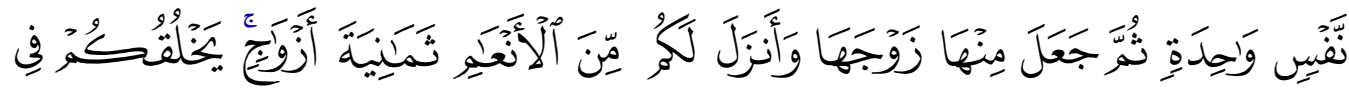

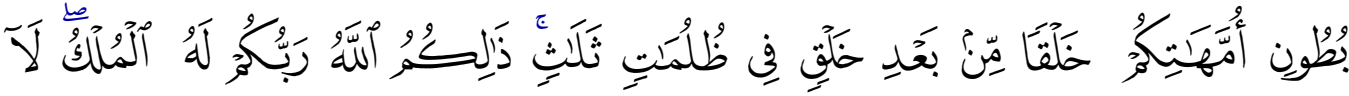

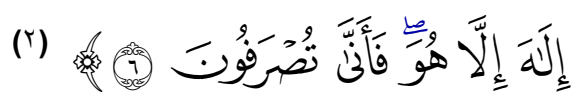

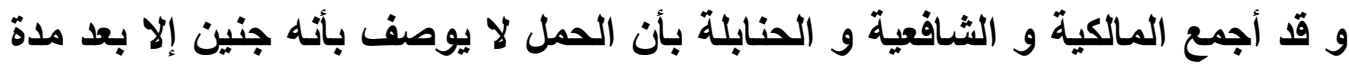

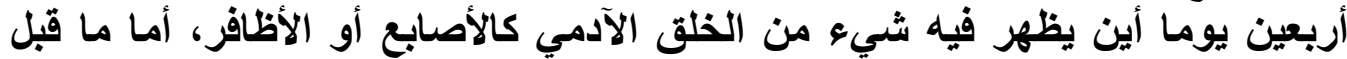

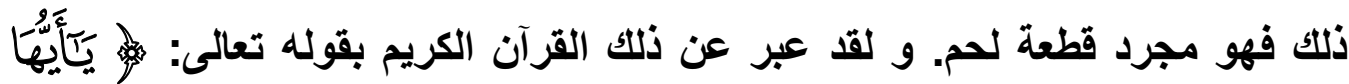

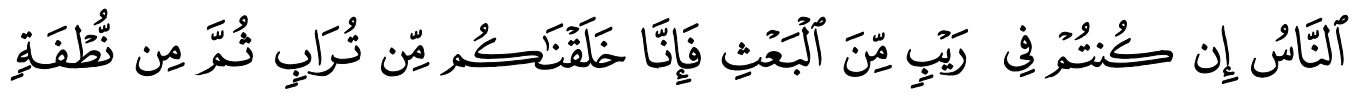

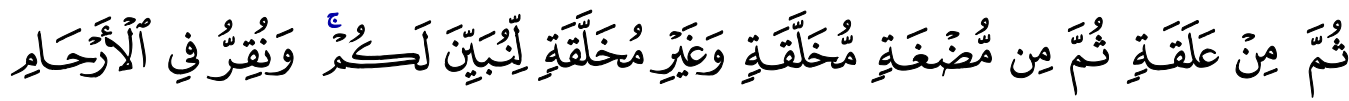

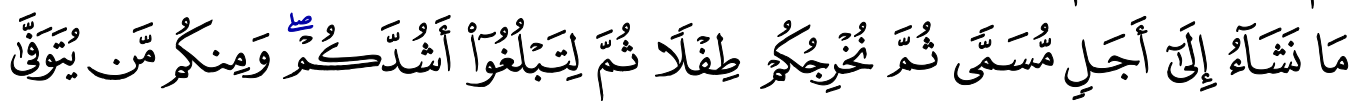

( (1) أميرة عدلي، أمير عيسى خالد ـ الحماية الجنائية للجنين- دار الفكر الجامعي ـ الإسكندرية ـ Y T (Y) سورة الزمر 7 


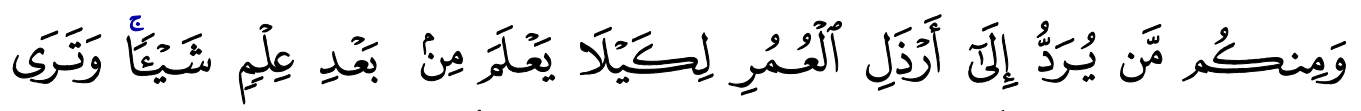

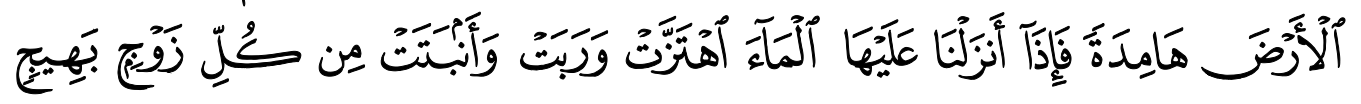

(1)

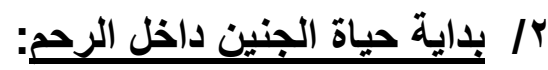

يرى معظم الققه الفرنسي أن المرأة تعد حاملا بمجرد تمام تلقيح البويضة بالحيو التهان

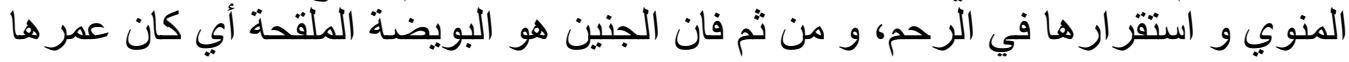
الزمني.

و قد أكدت محكمة النقض المصرية هذا الاتجاه حيث اعتبرت أن الإسقاط يعد جنائيا قبل أن يتشكل الجنين أو تدب فئه الفضه الحركة (؟) .

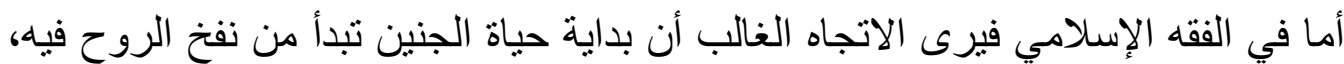

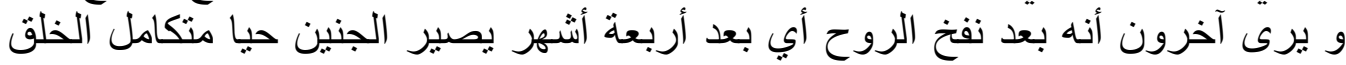

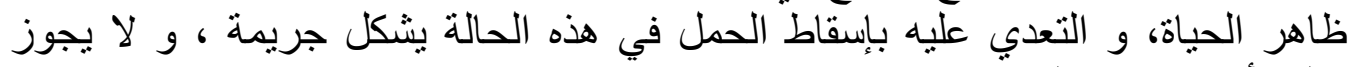
فعله لأنه حر ام إلا لضرورة العدي عليه بإنقاط.

\section{ثانيا : تحديد موعد نهاية وصف الجنين النين \\ الم في القانون الوضعى:}

عندما يولد الجنين و ينفصل عن الرحم فانه يكسب صفة جديدة كانسان حي، و متى بلغ الغين هذه المرحلة زالت عنه الحماية المقررة للجنين و حلت التهل محلها الحماية الجنائية المقررة لجسم الإنسان. و هناك جانب من الفقه يرى نهاية وصف الجنين بتمام و لادته، بينما يرى آخرون أنه الإنه الوصف ينتهي ببداية عملية الو لادة.

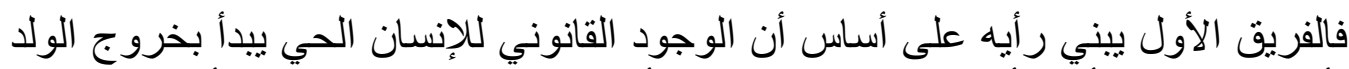

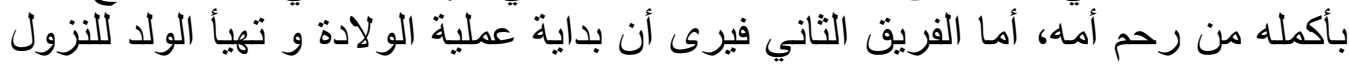

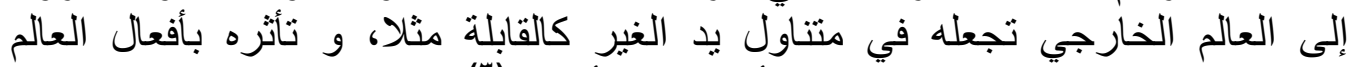

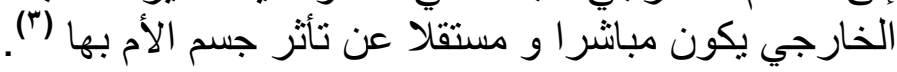

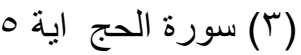

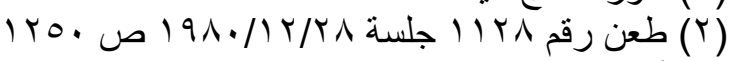

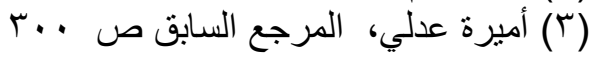


و على هذا فقد اختلف الفقهاء و علماء الطب في التعدي على المولود في اللحظة التي

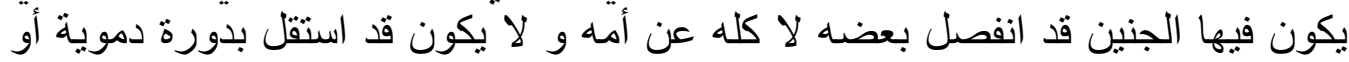

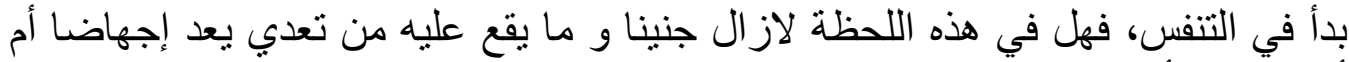

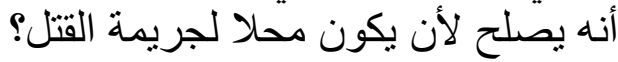

يتفق الفقه على أن الحياة بالمفهوم الجنائي تبدأ ببداية عملية الولادة الطبيعية لا بتمامها،

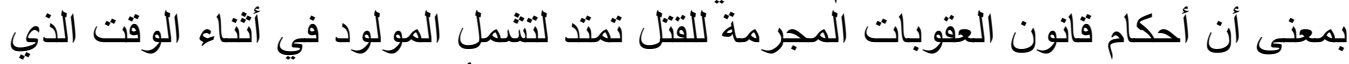

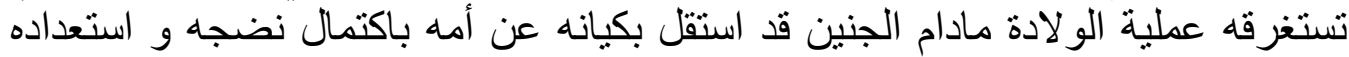

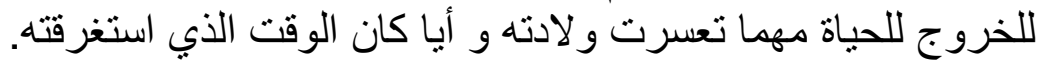

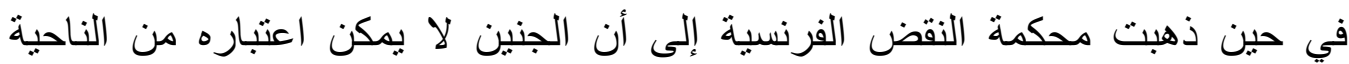

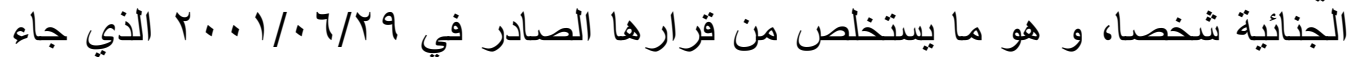

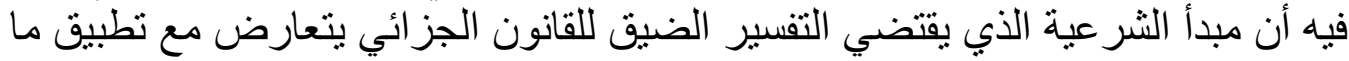

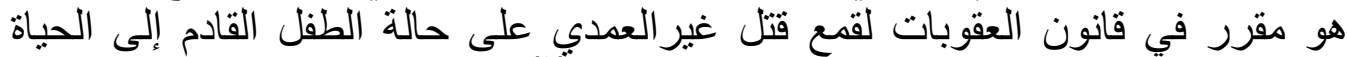

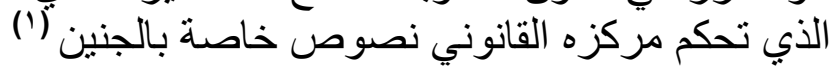

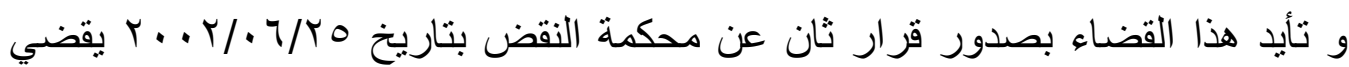

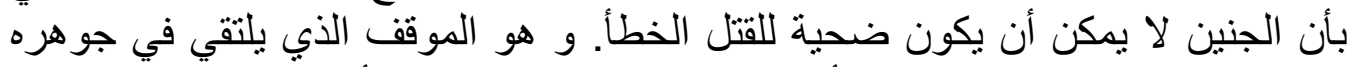

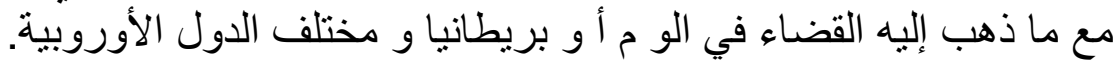

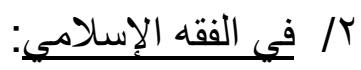

يرى فقهاء الإسلام أن نهاية سريان أحكام الحماية المقررة للجنين تنتهي بتمام عملية

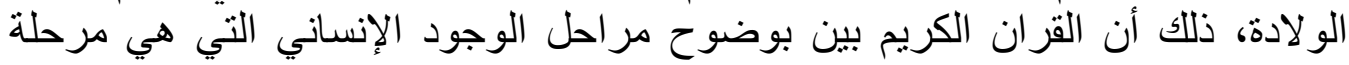

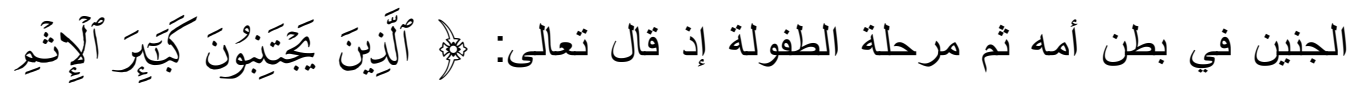

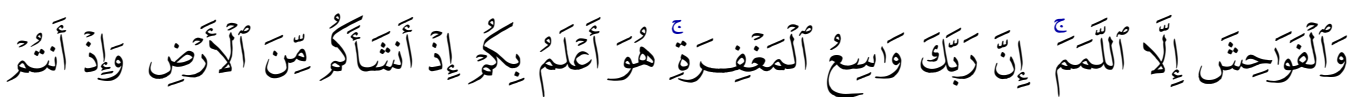

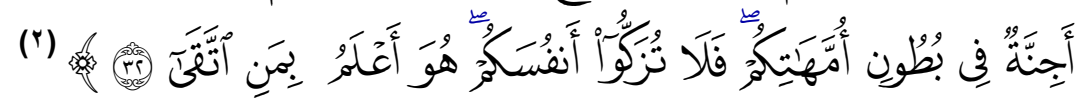

(1) أحسن بوسقيعة الوجيز في القانون الجزائي و الجرائم ضد الأمو ال وجر ائم ضد الاشخاص - دار

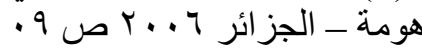

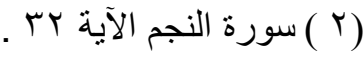


و تبدأ مرحلة الطفولة بخروج الجنين و انفصاله عن أمه، بعد أن يمر بعدة مر احل داخل الرحم إذ يكون نطفة ثم علقة ثم مضغنة

و بذلك فان جريمة الإجهاض لا تقع إلا على جنين لم ينفصل بعد عن الرحهة الرحم، بينما

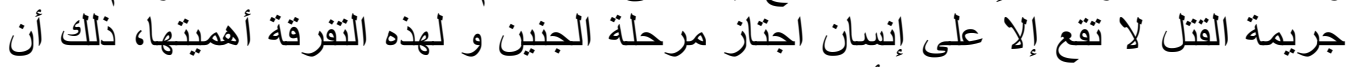

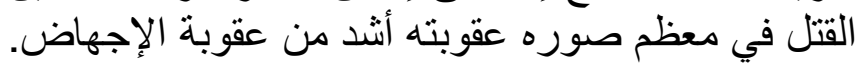

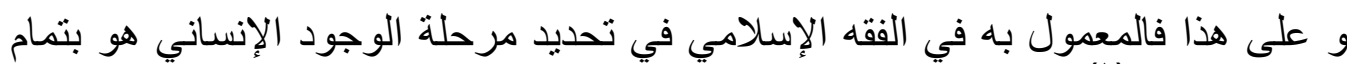

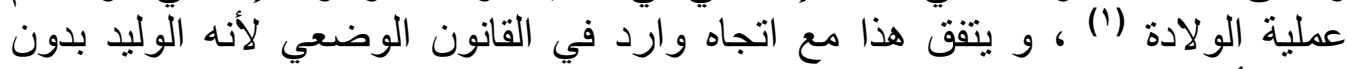

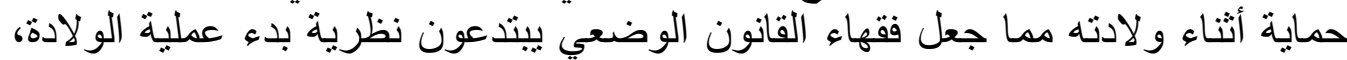

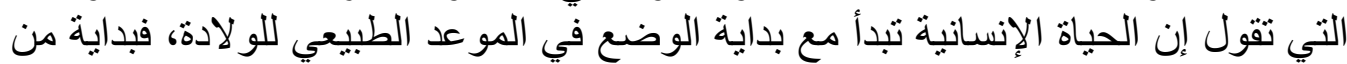

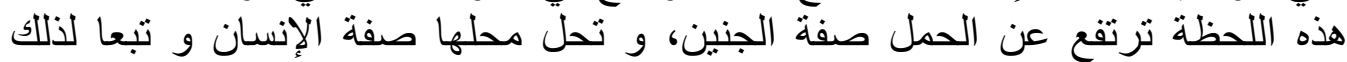

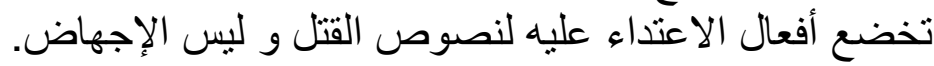

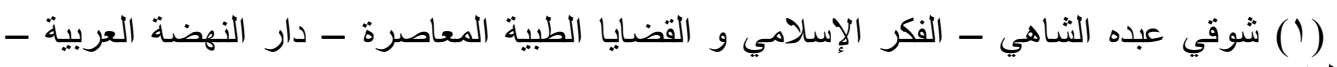

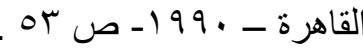


مجلة كلية الثريعة والقانون بتفهنا الأثراف ـ دقهلية العدد الثالث والعشرون لسنة اب ـ بم الجزء الأول

\section{المطلب الثنانبي}

\section{مماية حق الجنـين في الهياة داغل و خارج الرحم}

\section{أولا : وجود الجنين داخل الرحم}

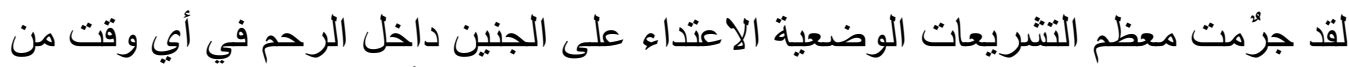

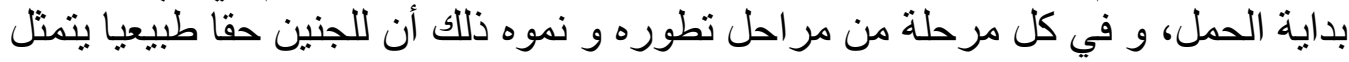

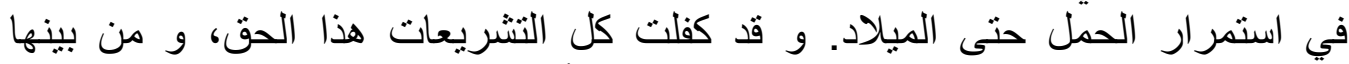

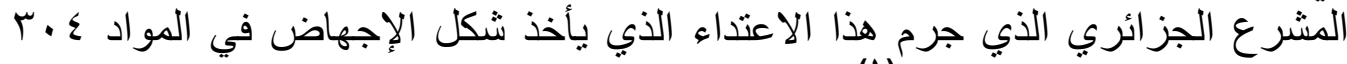

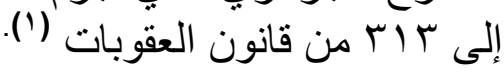

و كذللك الحال بالنسبة للتشريع الفرنسي أين نص قانون الصحة العامة على أنه لا يجوز

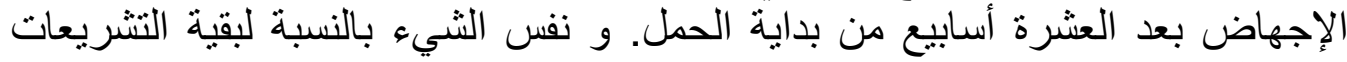
التي سلف ذكر ها في المقدمة.

هذا و لم تقف حماية حق الجنين في الحياة عند هذا الحد، بل امتدت في كثير من البلدان

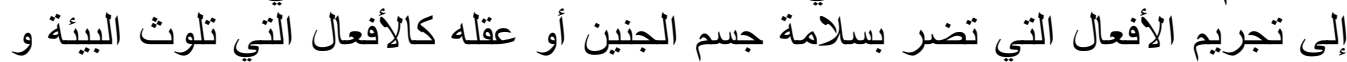

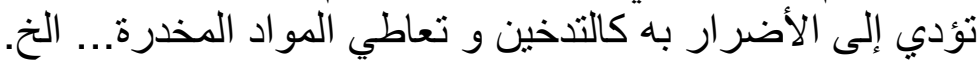

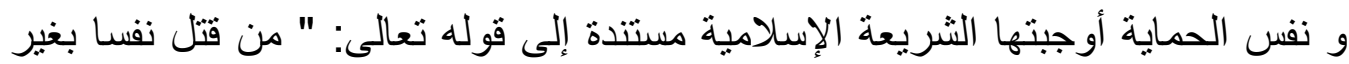

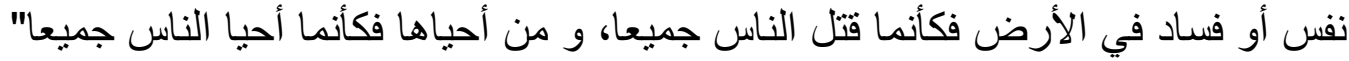

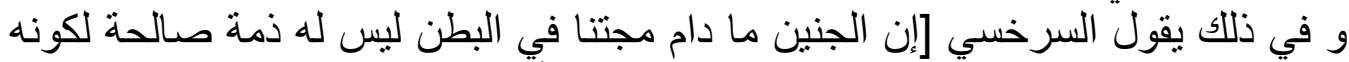

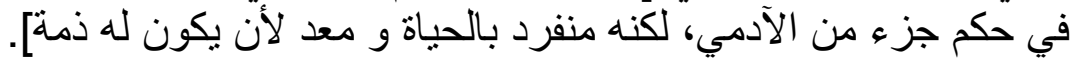

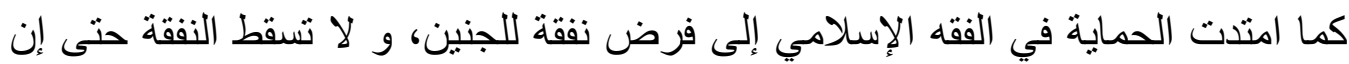

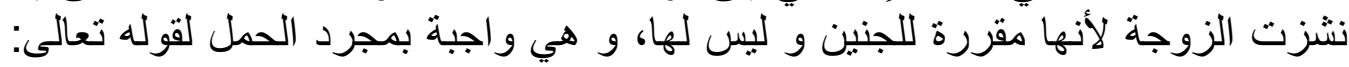

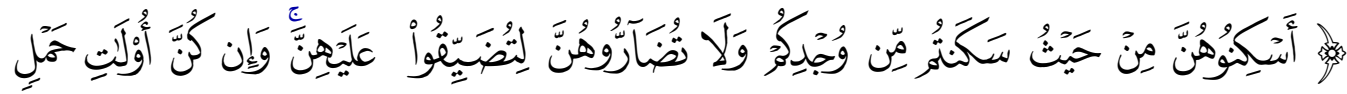

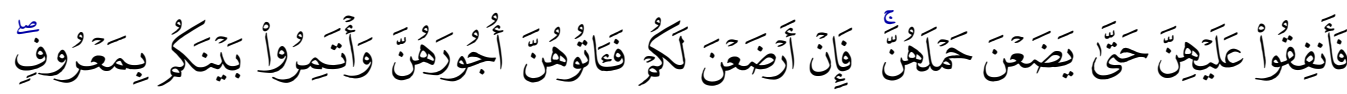

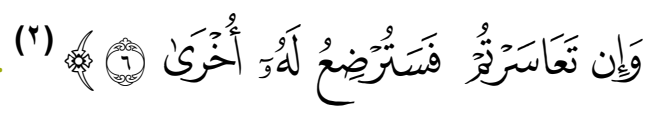

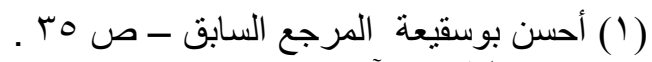$$
\text { (Y) سورة الطلاق الآية ؟؟. }
$$ 


\section{ثنانيا: البويضات الملقحة في الأنابيب}

في هذه الحالة التي نحن بصددها توجد بويضة مخصبة إلا أن عملية التخصيب تتم التحان

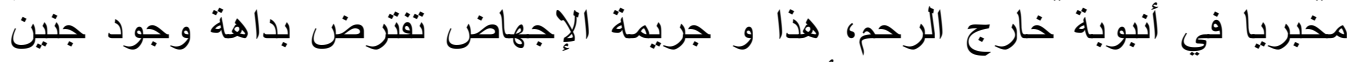

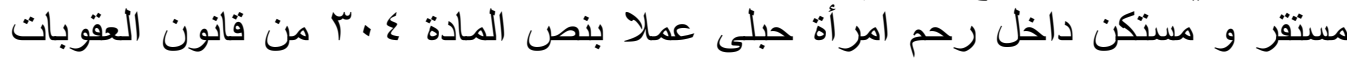

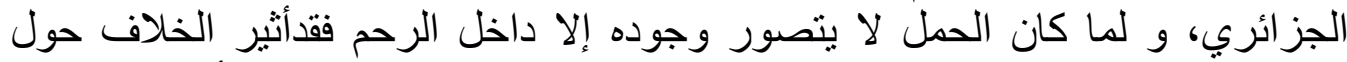

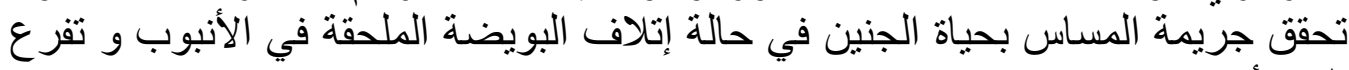
إلى رايين:

1ـ البويضات الملحقة في أنابيب خارج رحم المرأة ليست أجنة:

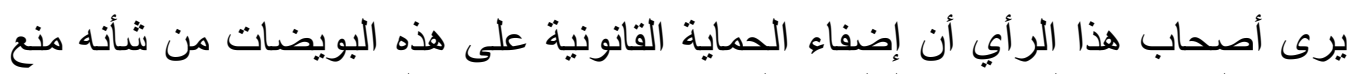

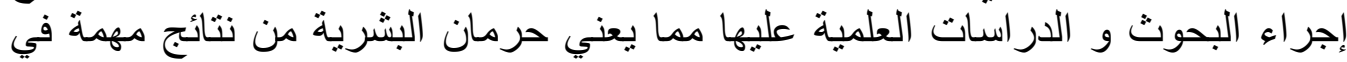

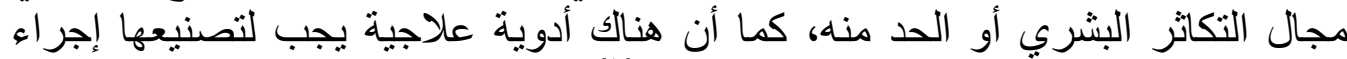

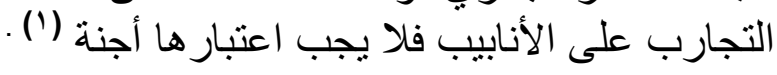
r- البويضات الملقحة في الأنابيب ما هي إلا أجنة:

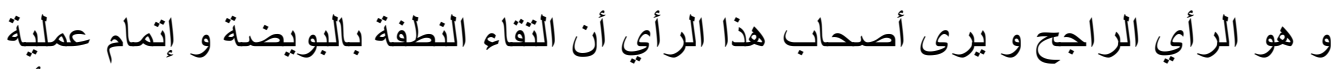

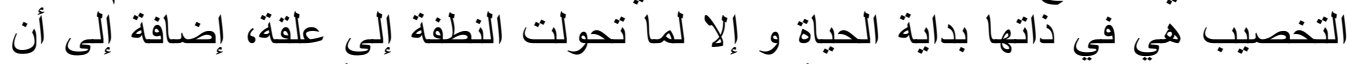

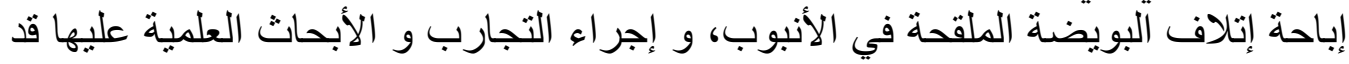

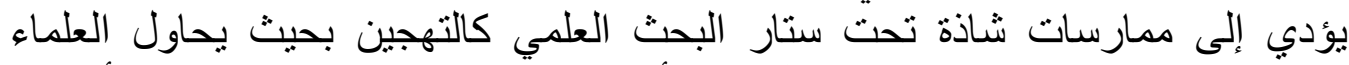
تخليق كائن مختلط بين الإنسان و الحيوان أو استنساخ صورة إنسان إنسان حيا كان أو ميتا

(r) الخ

و بذلك بطالب أصحاب الرأي بإصدار تشريع خاص ينشأ نصوصا جديدة تحمي هذه

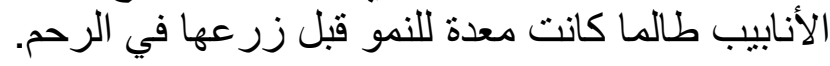

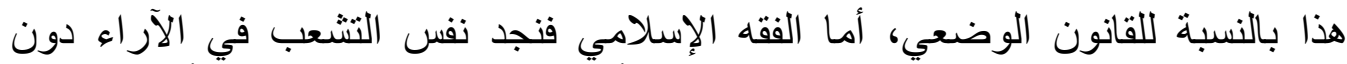

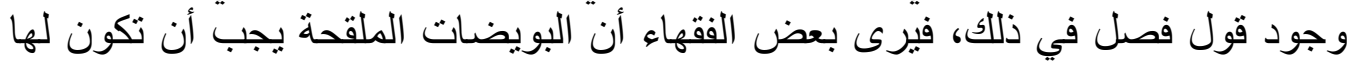

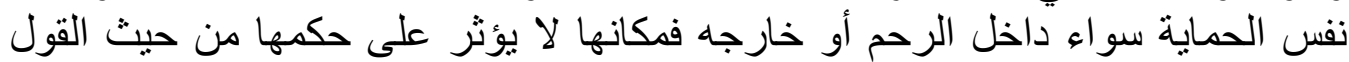

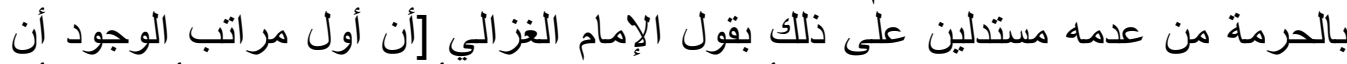

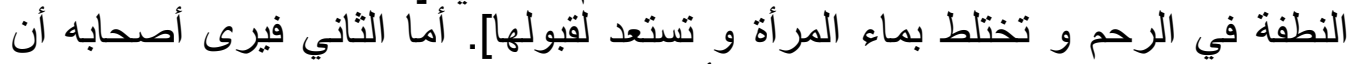

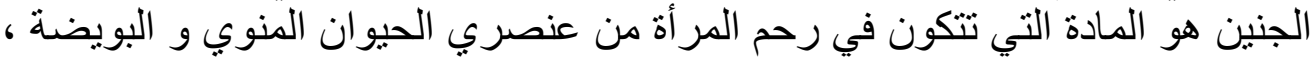

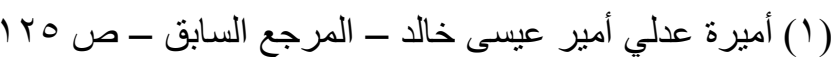

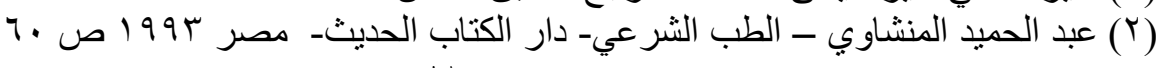


مجلة كلية الثريعة والقانون بتفهنا الأثراف ـ دقهلية العدد الثالث والعشرون لسنة اب ـ بم الجزء الأول

و من ثم فإن البويضة الملقحة في الأنابيب لا تعتبر جنينا بالمعنى الثر عي إلا من تاريخ زرعها في رحم المرأة الر اغبة في الحمل بهذه الطريقة.

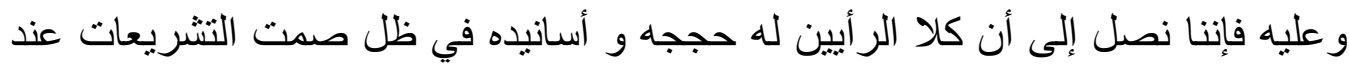
هذه النقطة، ربما لحداثتها خاصة عندنا.

\section{ثالثاً : حماية حق الجنين في ضوه الممارسات الطبية المستحدثة / المقصود بالممارسات الطية المستحدثة}

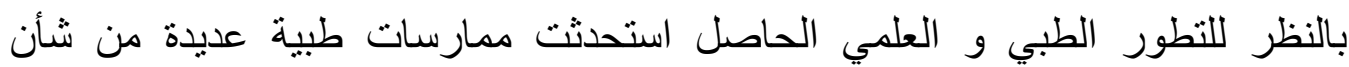

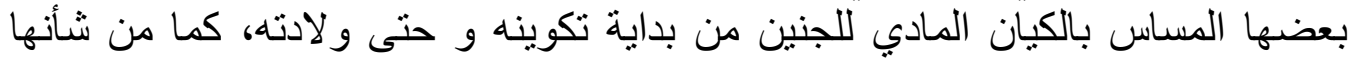

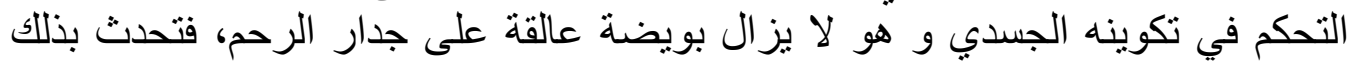

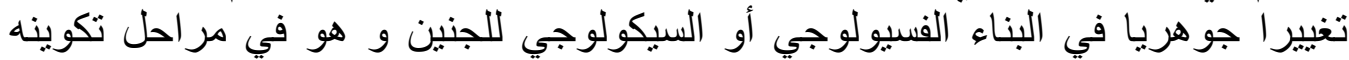

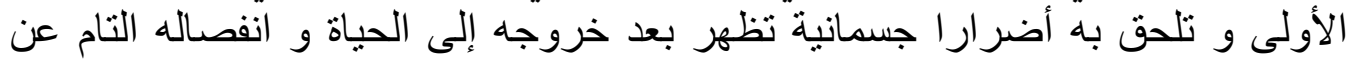

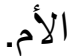

فقد تتخذ صورة التشويه في الخلقة أو إضافات وراثية لم تكن موجودة أصلا في في التي

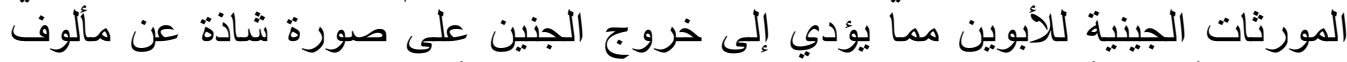

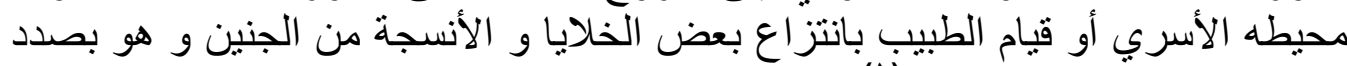

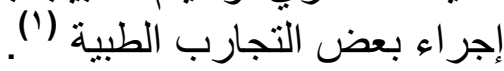

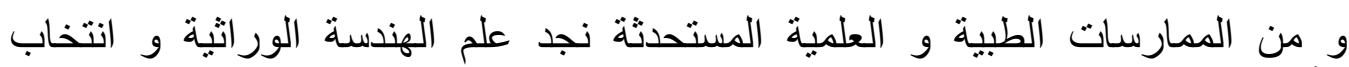

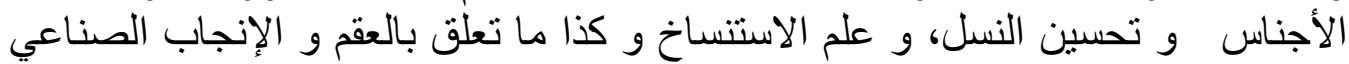

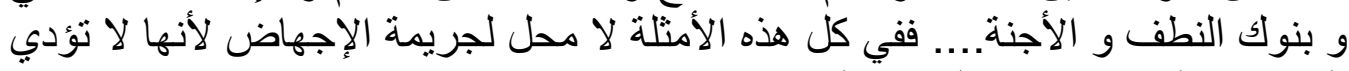
إلى موت الجنين و انفصاله عن الرحمة الرحم.

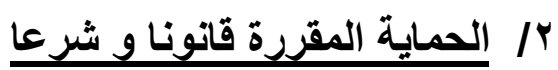

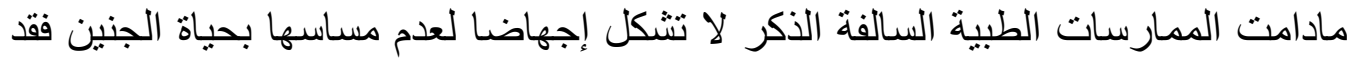

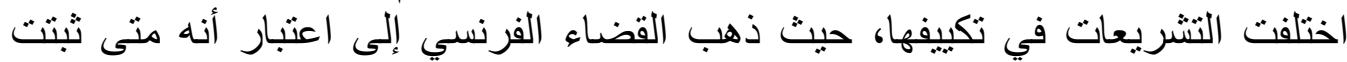

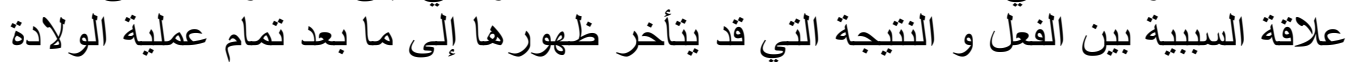

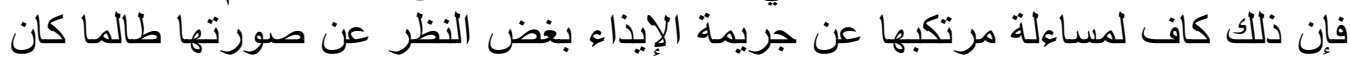

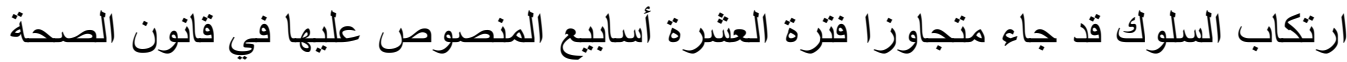

(1) رضا عبد الحليم عبد المجيد ـ الحماية القانونية للجنين البشري ـ دار النهضة العربيةـ القاهرة-

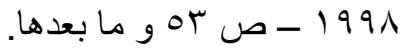
$-\triangle \wedge \vee=$ 
العامة، و من ثم فإن للجنين الحق في التعويض حتى و إن ولد و به إعاقة و تشوهات

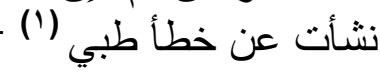

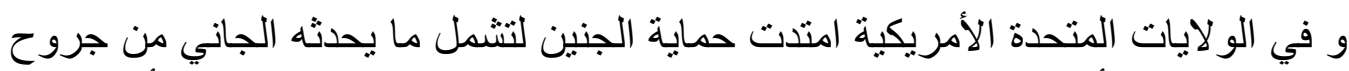

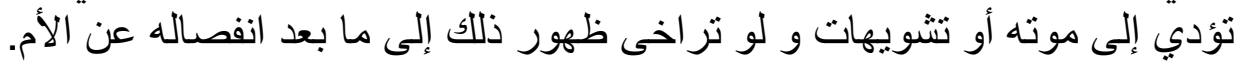

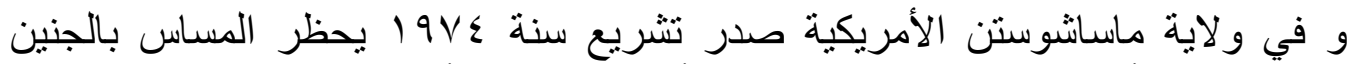
داخل الرحم لأغراض علمية و مخبرية، إذ أن له الحق في أن يولية يولد سليم البنية و على قيد بليد

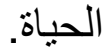

أما في مصر فيذهب الفقه الجنائي و قضاء النقض إلى أن تراخي حدوث النتيجة لا يقطع النقاء

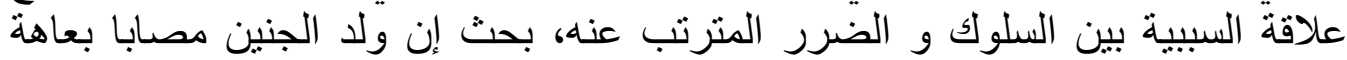

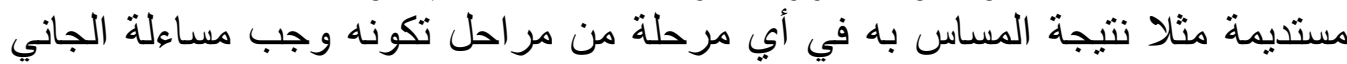
عن جريمة إحداث عاهة مستديمة.

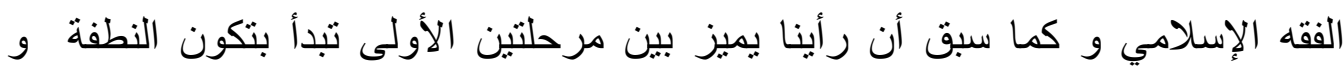

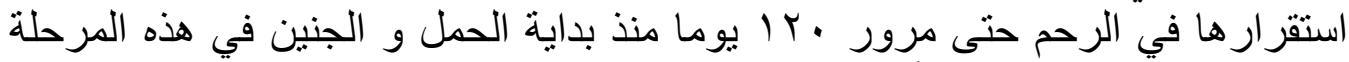

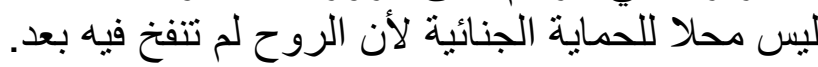

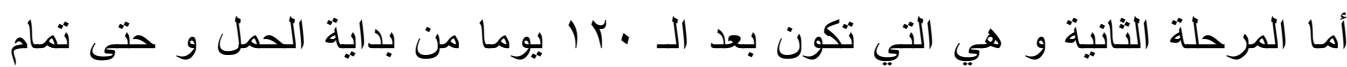

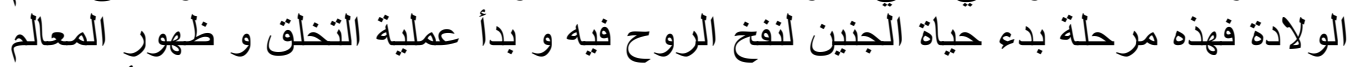

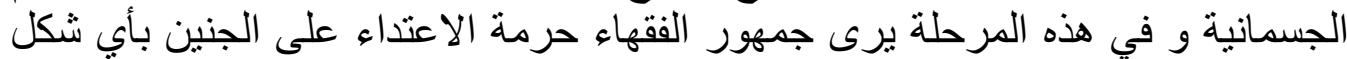

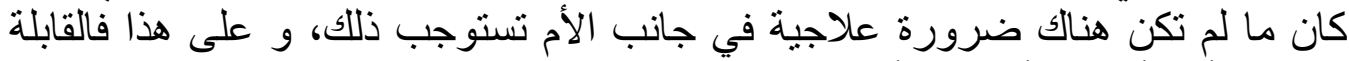

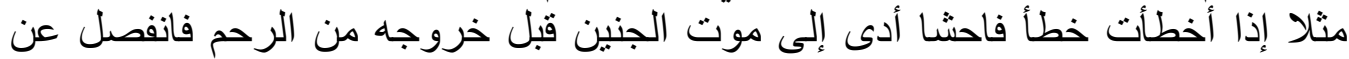

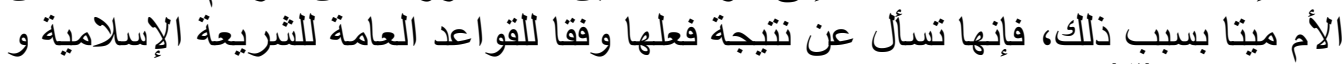

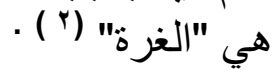

\section{رابعا : حماية حث الجنين في مجال المعاملة العقابية للأم الحامل / / مظاهر الحماية الجنائية في المعاملة العقابية للأم الحامل}

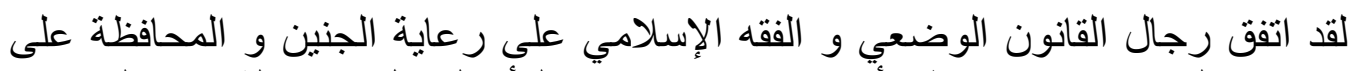

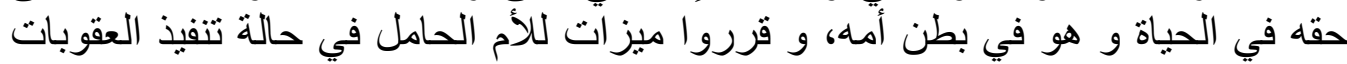

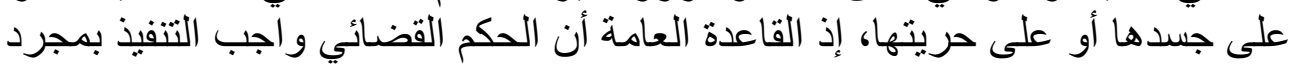

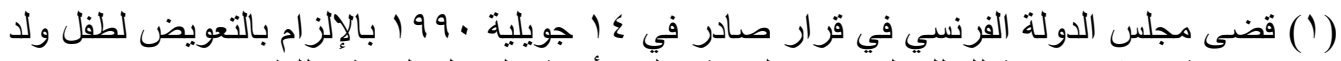

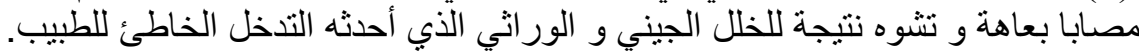

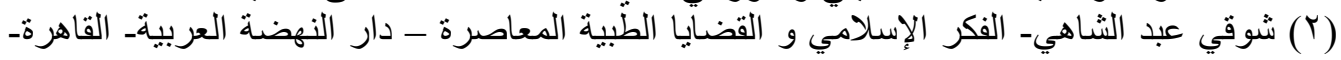


مجلة كلية الثريعة والقانون بتفهنا الأثر اف ـ دقهلية العدد الثالث والعشرون لسنة اب ـ ب م الجزء الأول

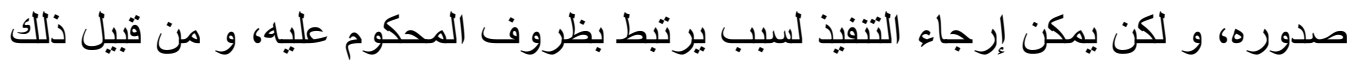

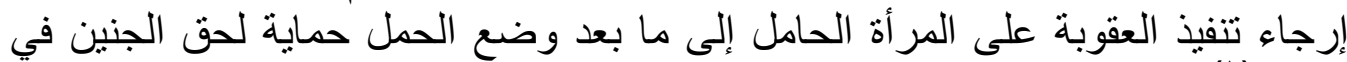

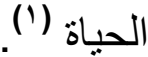

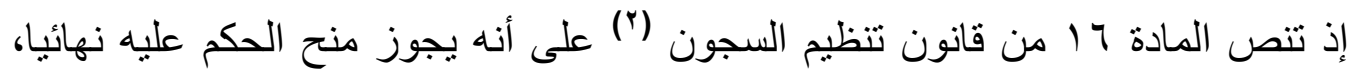

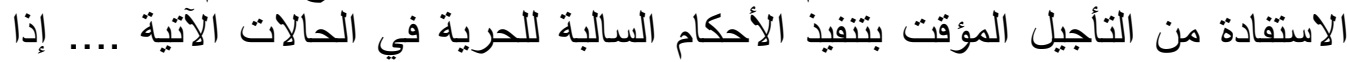

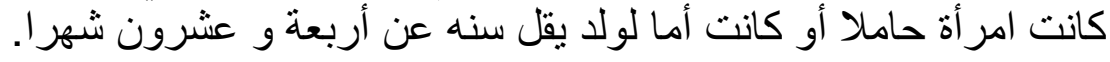

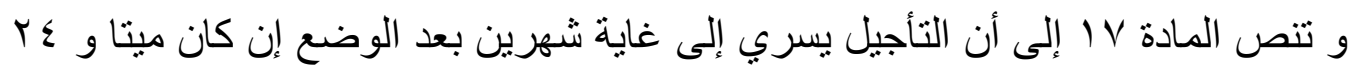

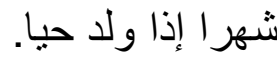

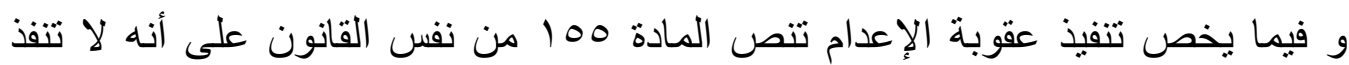

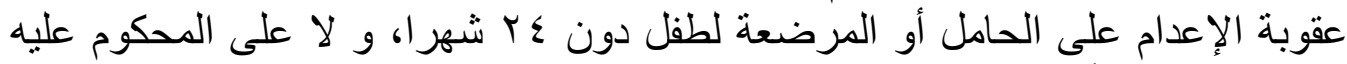

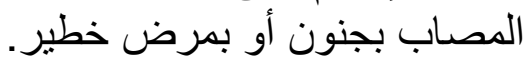

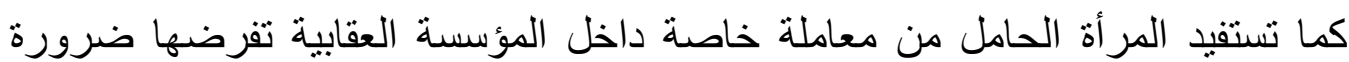

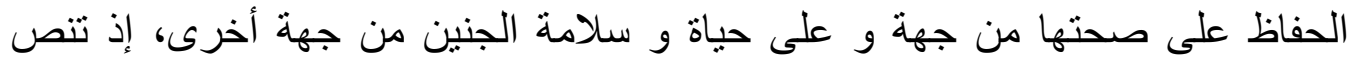

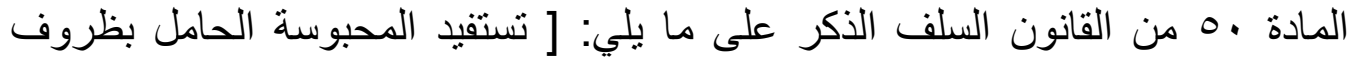

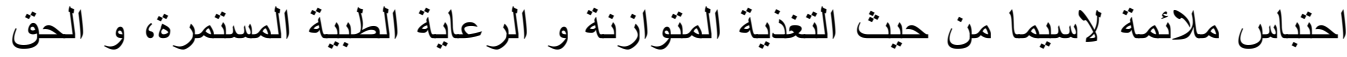

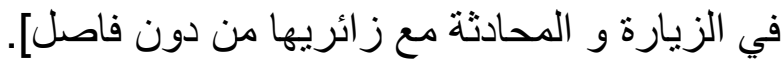

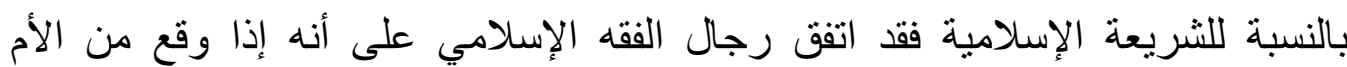

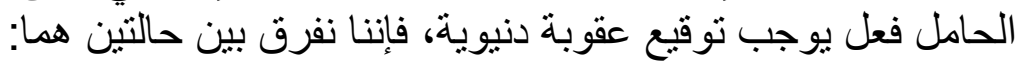

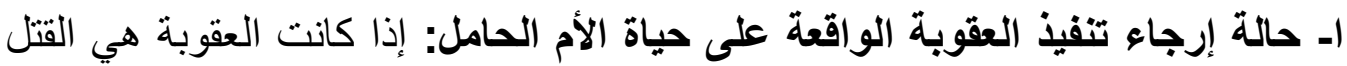

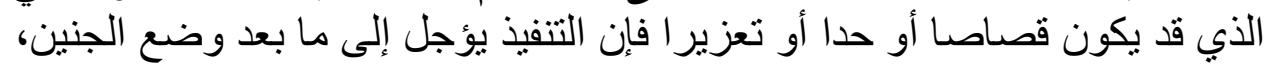

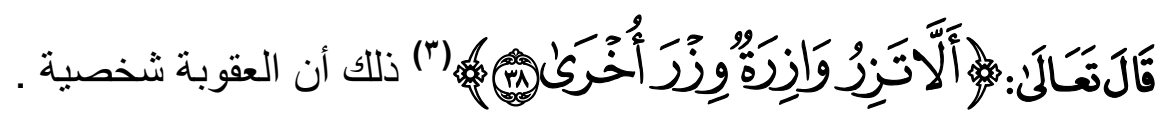

(1) إسحاق إبراهيم منصور - الموجز في علم الإجرام و العقابـ د م ج - الجزائر 9199 اــ ص .194

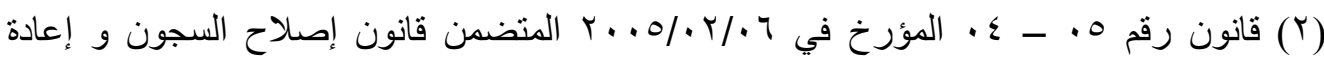

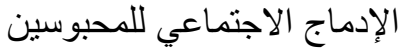

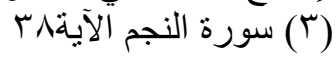




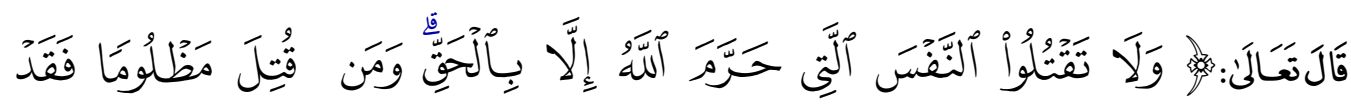

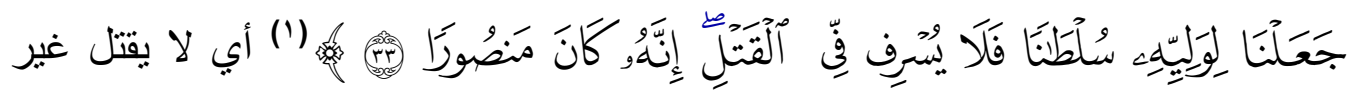

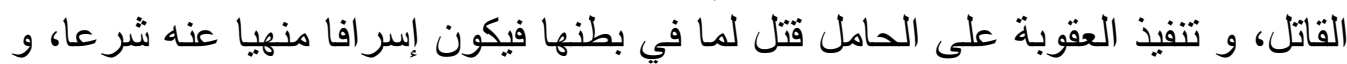
النهي يفيد التحريم. تصنئ.

و روي عن الرسول صلى الله عليه و سلم أنه قال: " المرأة إذا قتلت عمدا لا تقتل حتى ولى تضع مأ في بطنهاو حتى تلكفل ولى ولدها".

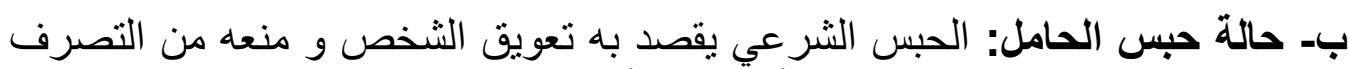

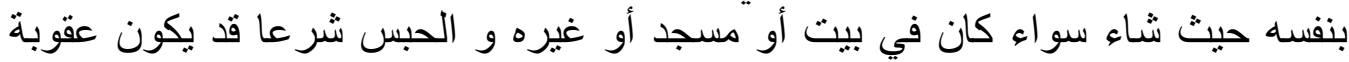

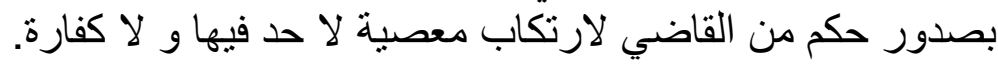

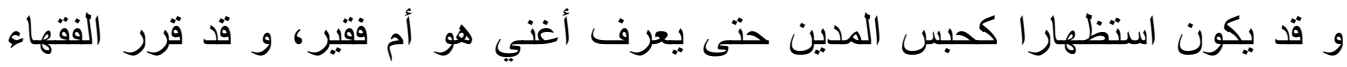

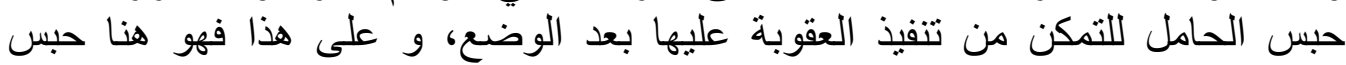
احتباطي.

و بذلك يتفق القانون مع الفقه الإسلامي في مبدأ الشخصية حماية لحق الجنين في الحياة،

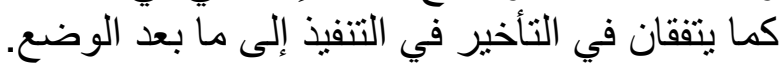
ثناتيا : إباحة ما يعد جريمة حماية لحق الجنين في الحياة

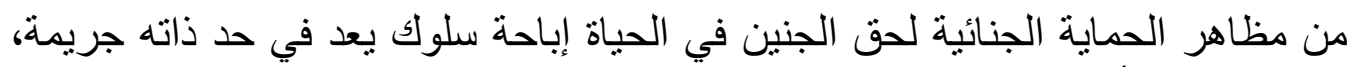

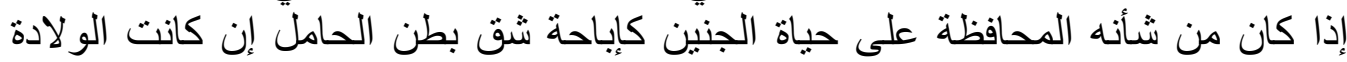

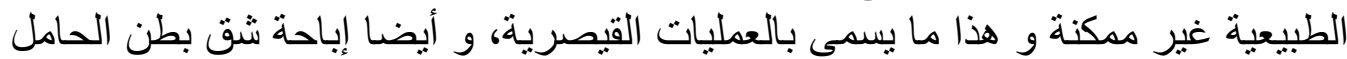
المتوفاة لإخر اج الجنين الحي.

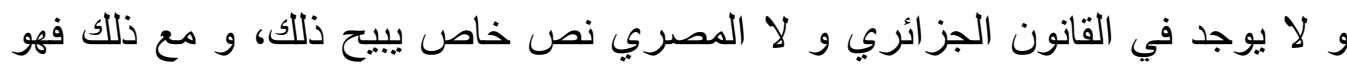

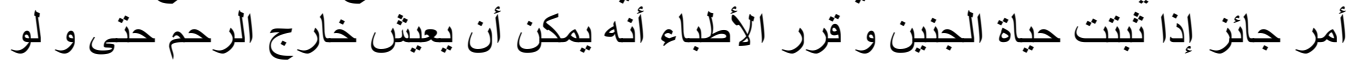

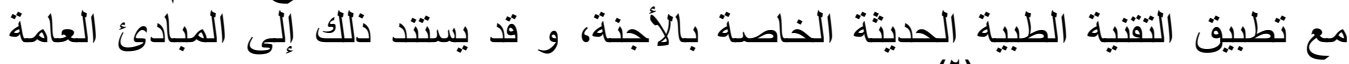

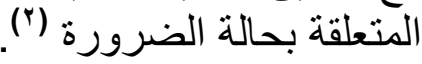


مجلة كلية الثريعة والقانون بتفهنا الأثراف ـ دقهلية العدد الثالث والعثرون لسنة اب ـ ب م الجزء الأول

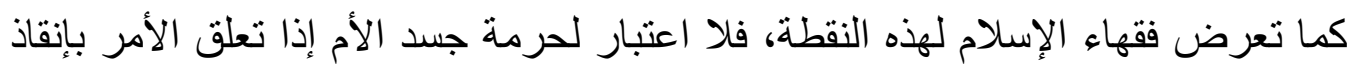

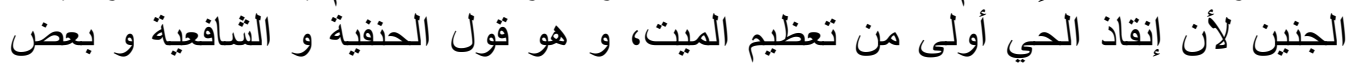

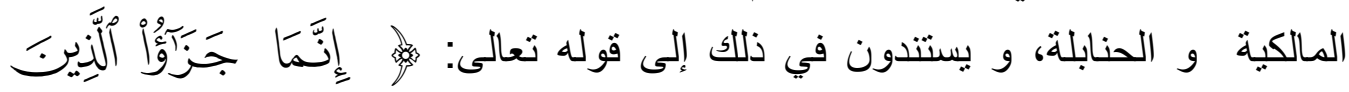

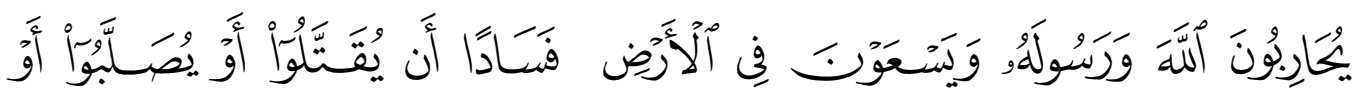

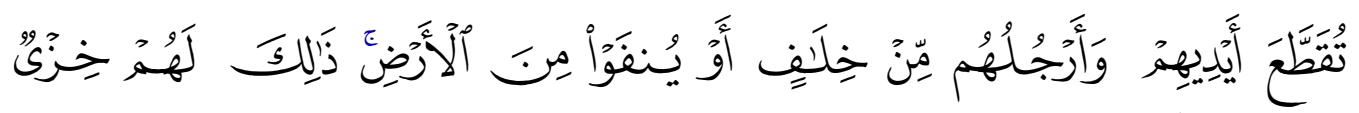

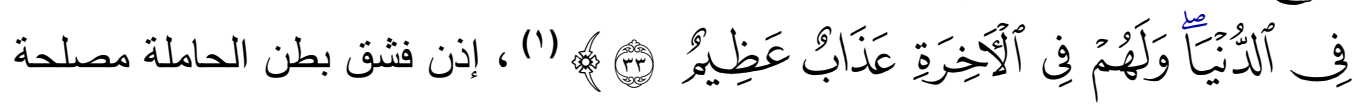

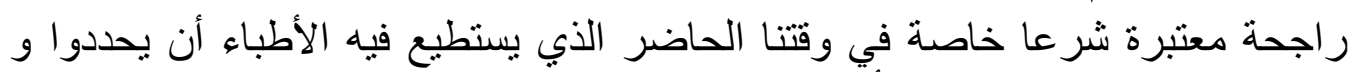
بكل دقة ما إذا كان الجنين حيا أو ميتا.

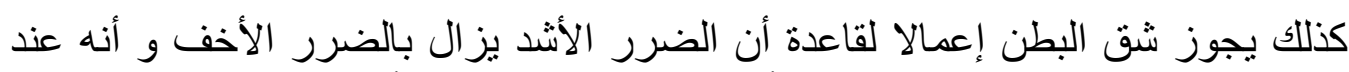
تعارض المفسدة مع المصلحة ير اعى أعظمها ضرر العار أنكاب أخفها. 


\section{المطلب الثالث}

\section{1الإجهاضر كنموذج لجريمة التعدي على الجنين}

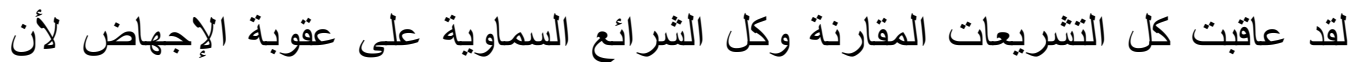

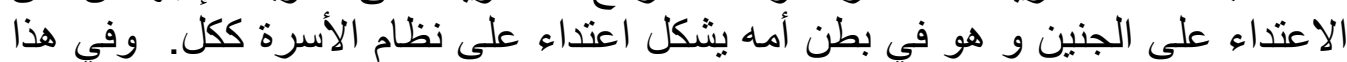

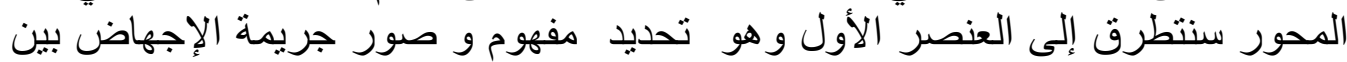

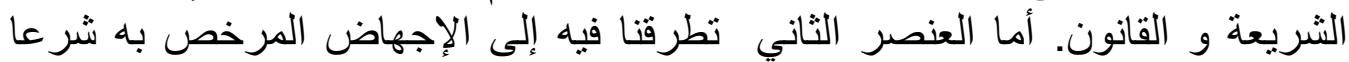

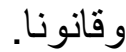

\section{اولا مفهوم و صور الإجهاض بين الشريعة و القانون

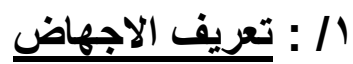

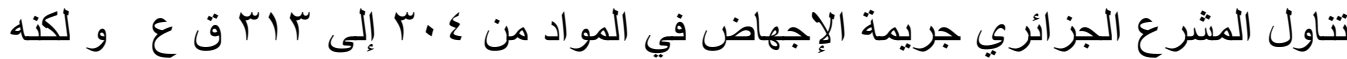

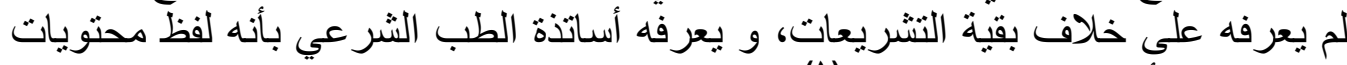

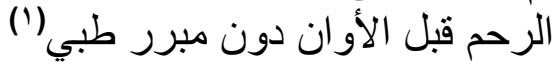

و قد عرفته محكمة النقض المصرية على أنه تعدد إنهاء حالة الحمل قبل الأوان.

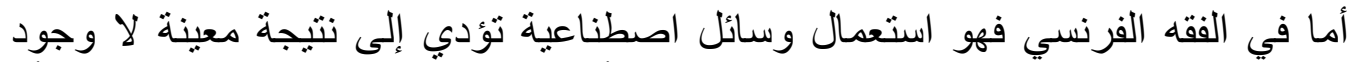

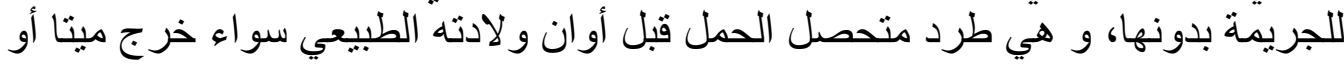
حياو لكنه غير قابل للحياة.

و يعرفه الفقه الإنجليزي بأنه تدمير معتمد للجنين في الرحم، أو و لادة سابقة لأوانها قصد

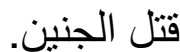

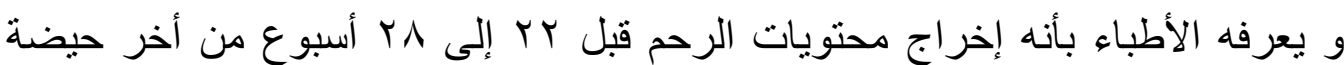

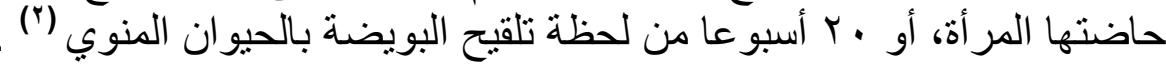

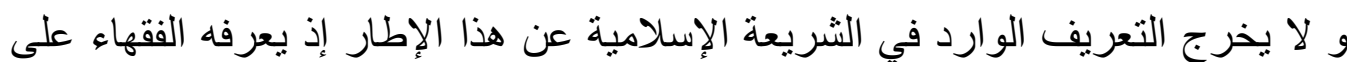

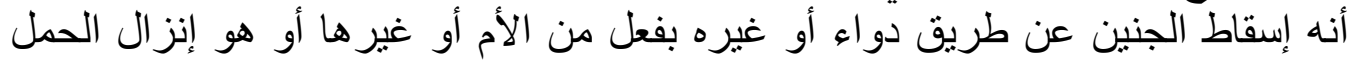

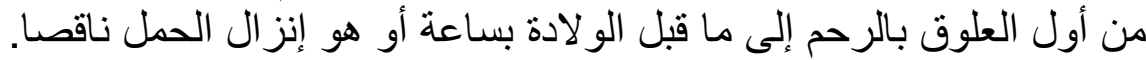
تاه / صور جريمة الاجهاض

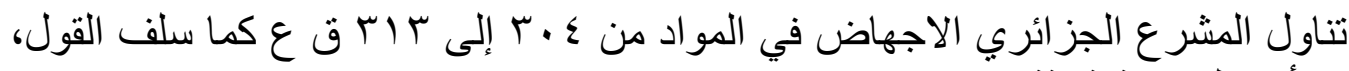
و تأخذ الجريمة ثلاثة صنور الترب الاجي:

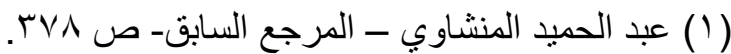

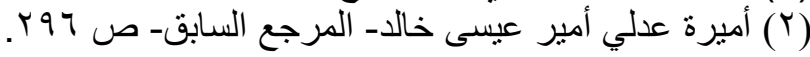


مجلة كلية الثريعة والقانون بتفهنا الأثر اف ـ دقهلية العدد الثالث والعشرون لسنة اب ـ ب م الجزء الأول

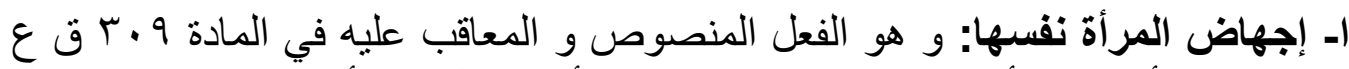

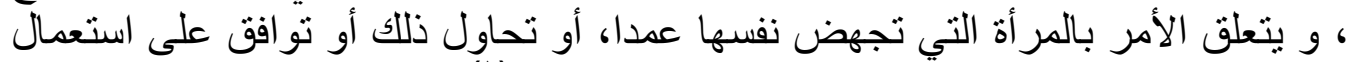

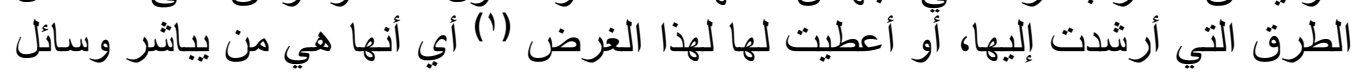
الإجهاض عن و وعي و إدر الك.

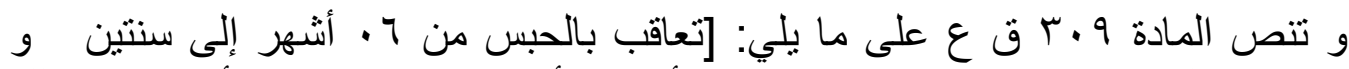

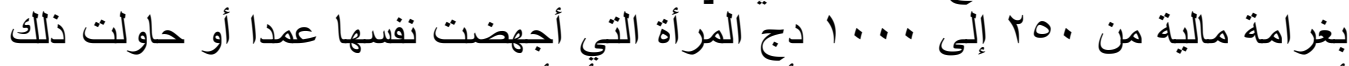

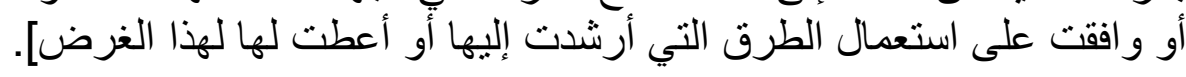

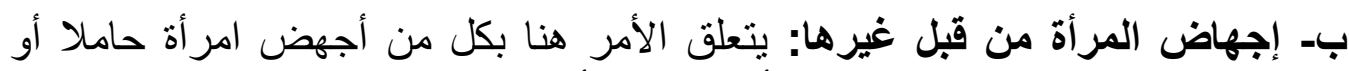

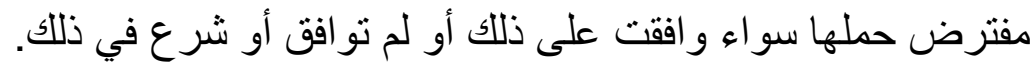

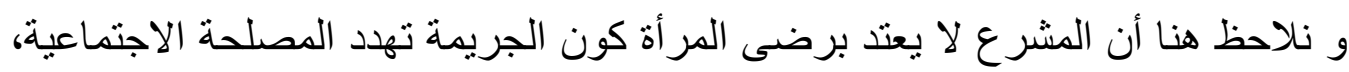

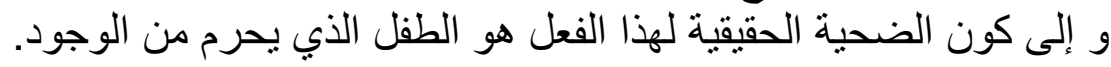

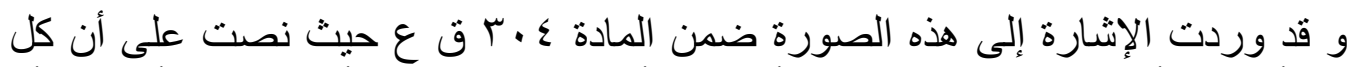

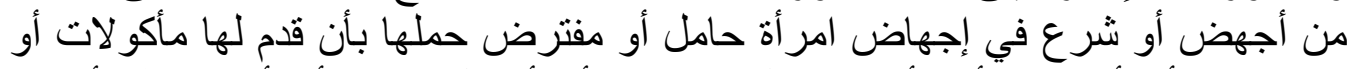

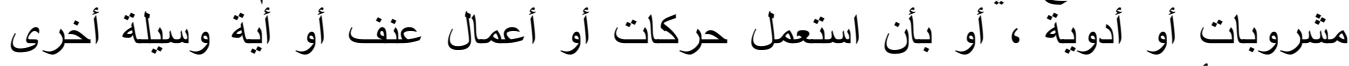

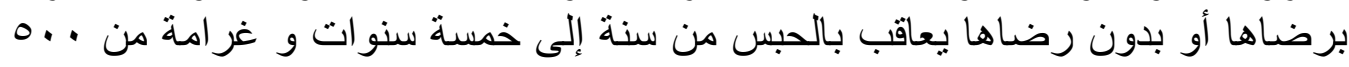

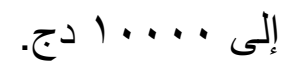

ج- التحريض على الإجهاض: في الحالات التي أخذ فيها قانون العقوبات الجزائري

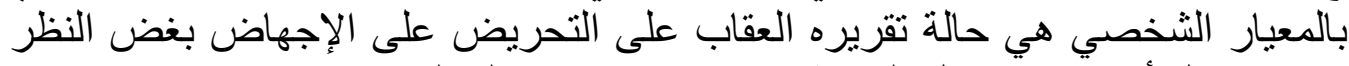

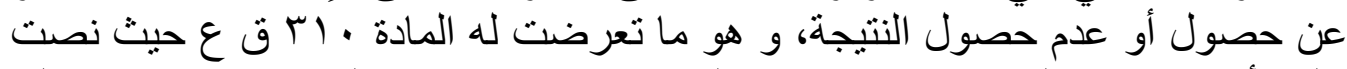

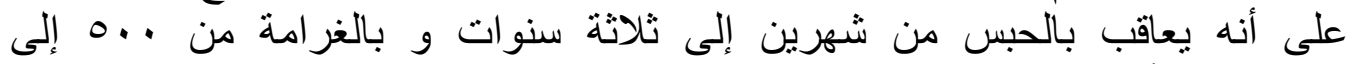

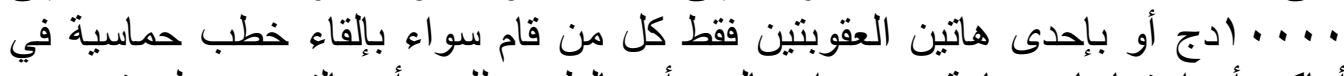

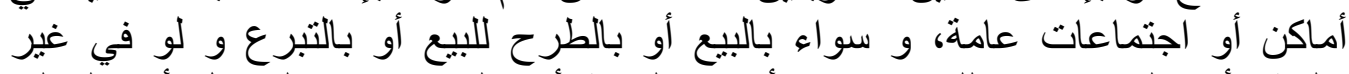

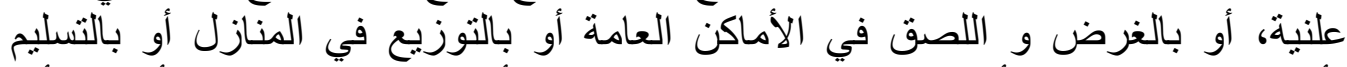

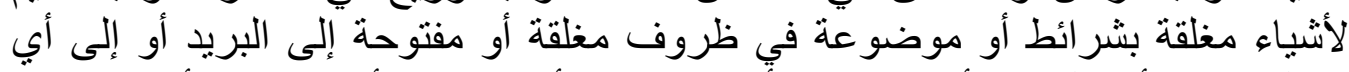

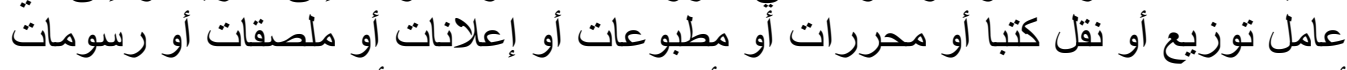

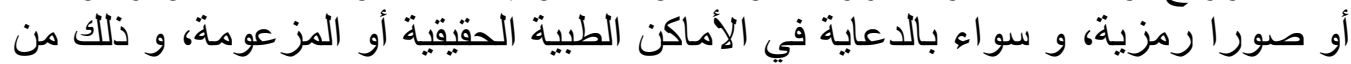
أجل التحريض على الإجهاض حتى و لو كان التحريض لـ لم ينتج أثره. 
و هكذا جاء النص شاملا لمعظم وسائل التحريض، و محتويا على العقوبة المقررة لها (')

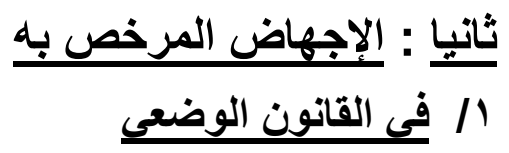

يتجه التشريع المقارن إلى عدم تجريم الإجهاض، و و كان المؤتمر الدولي التاسيع لقانون التاني

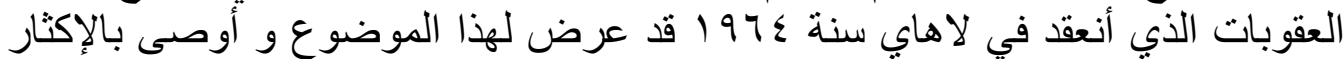

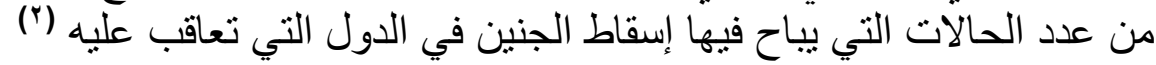

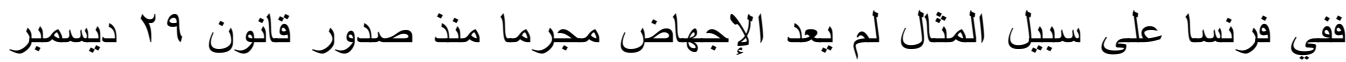

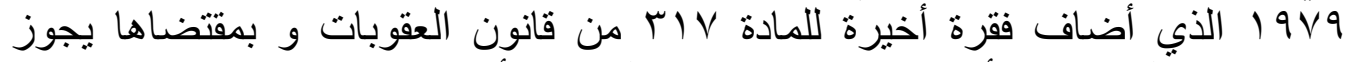

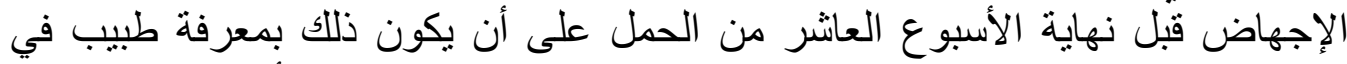

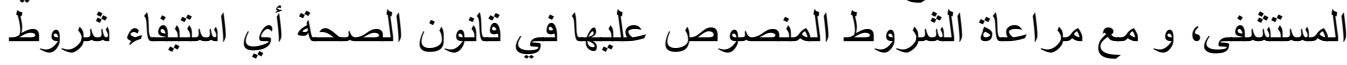

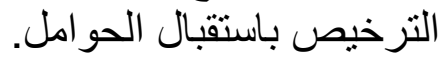

و في محيطنا العربي و الإسلامي، تعد تونس من الدول القلائل التي سنت تشريعا يتميز بالليونة في تجريم الإجهاض. أما التشريع الجزائري فيتميز على غرار التشريع المصري بالتشدد إزاء هذه الجريمة

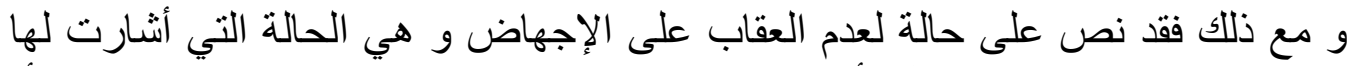

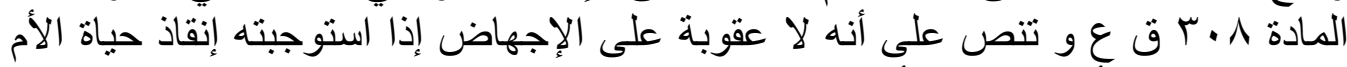

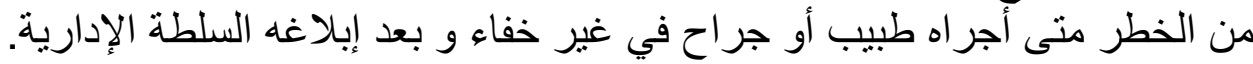

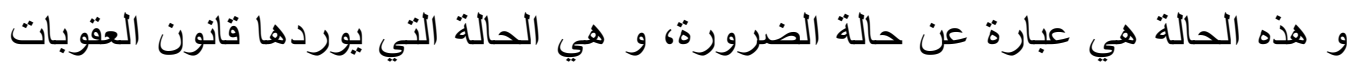

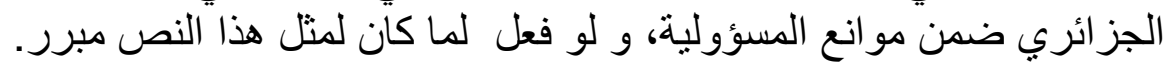

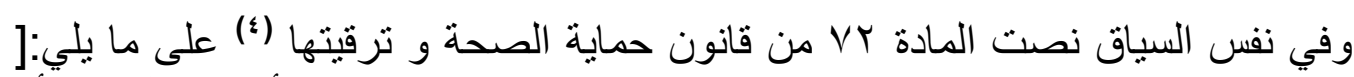

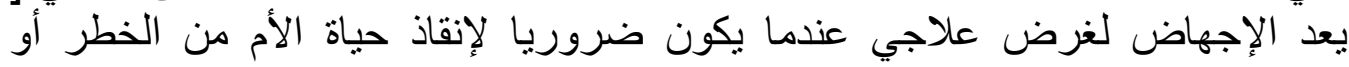

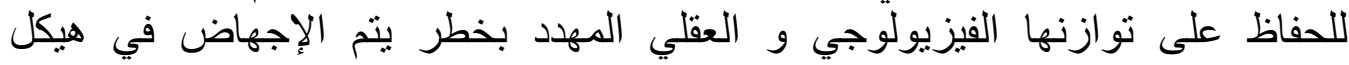
متخصص بعد فحص طبي يجري بمعية طبيب اختصاصي].

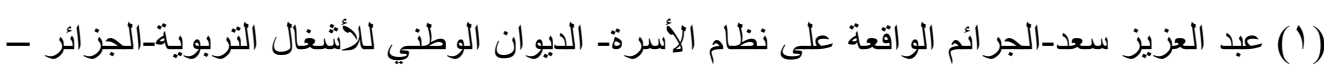
$0.0-r \cdot r$

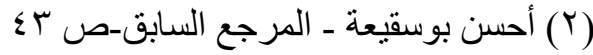

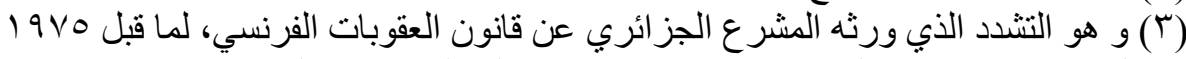

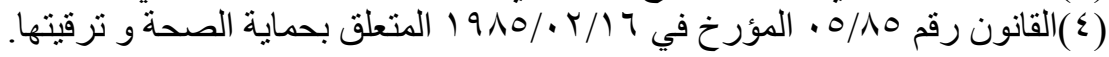


مجلة كلية الثريعة والقانون بتفهنا الأثر اف ـ دقهلية العدد الثالث والعشرون لسنة اب ـ ب م الجزء الأول

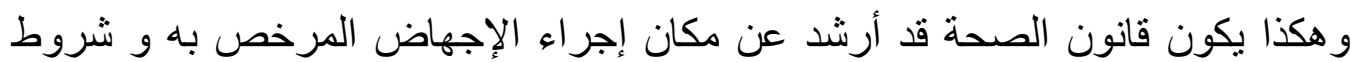

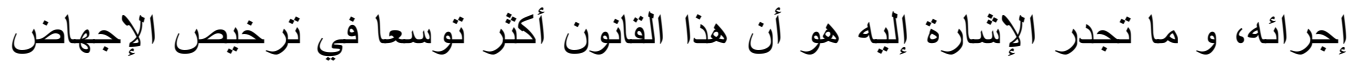

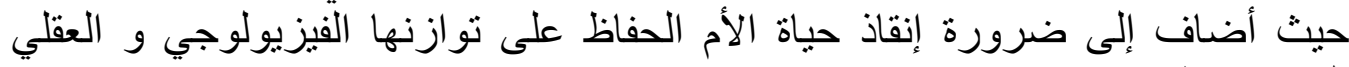

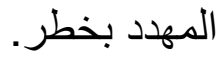

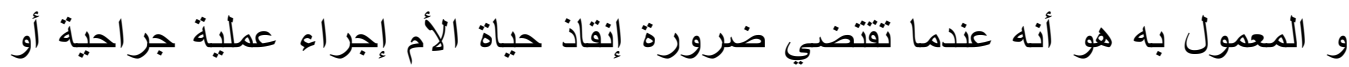

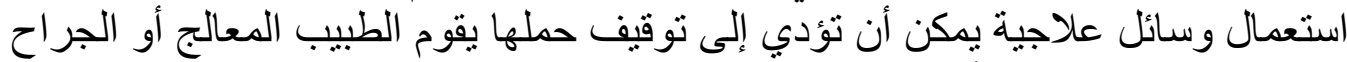

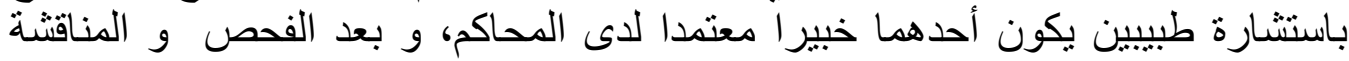

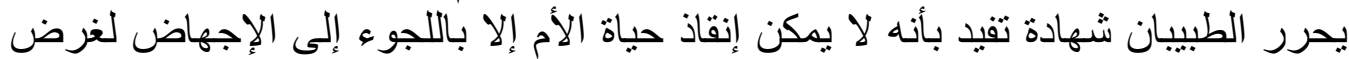
علاجي.

\section{r/ في الشريعة الإسلامية}

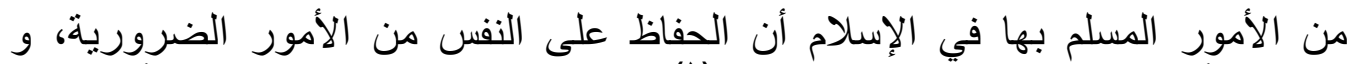

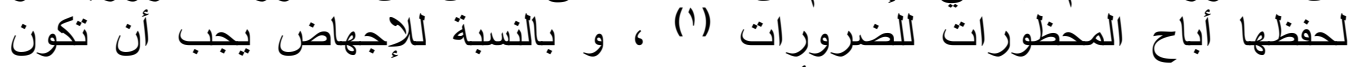

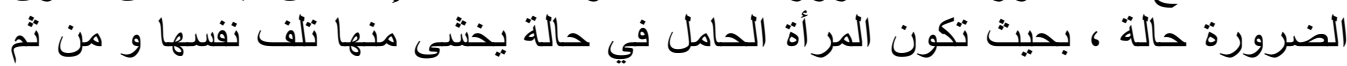

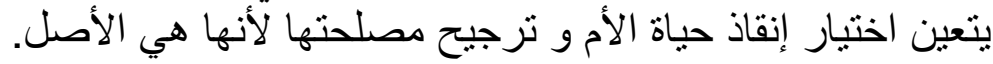

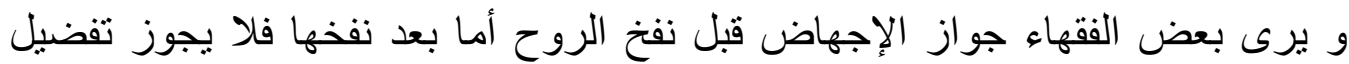

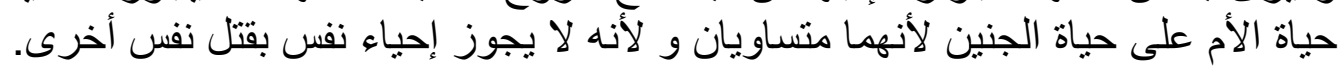
و نرى مما تقدم أن فقهاء القانون الوضعي يتفقون مع فقهاء الإسلام في أن حياة الجنين تابعة لحياة أمهه و متوقفة أنق عليها.

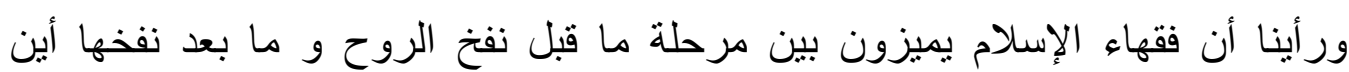

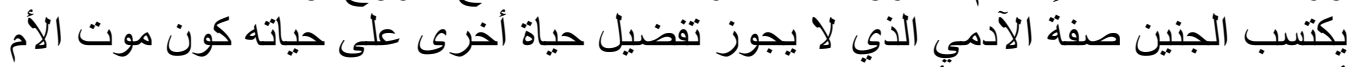

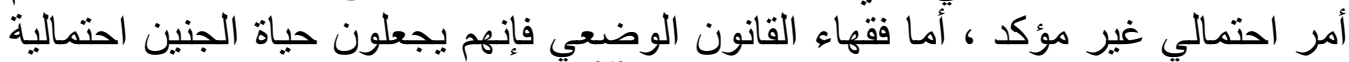

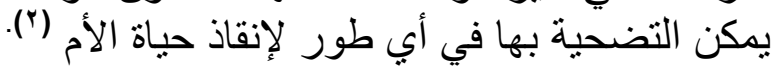

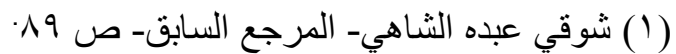

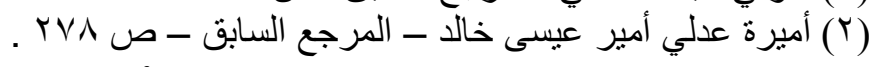




\section{الخاتمــة}

نصل في الأخير إلى أن كل حقوق الجنين محمية شرعاو قانونا بما في ذلك حقه في

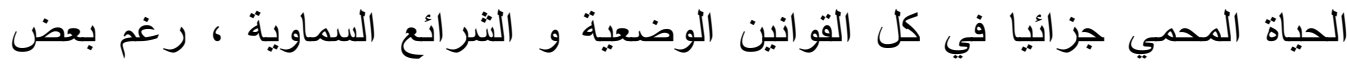

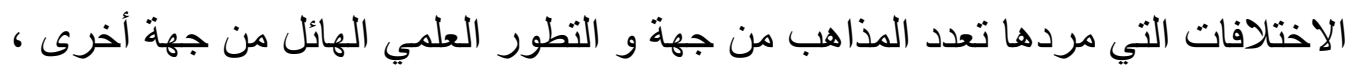
و هو ما رأيناه عند دراسة الممارسات الطبية المستحدثة و أطفال الأنابيب .

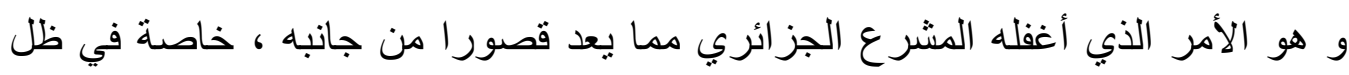

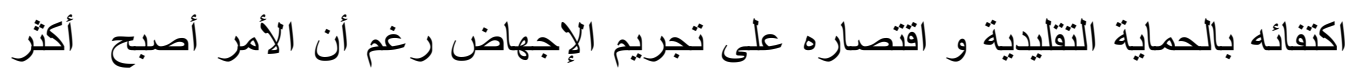

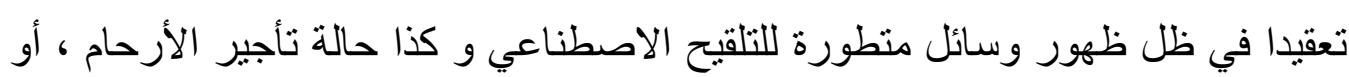

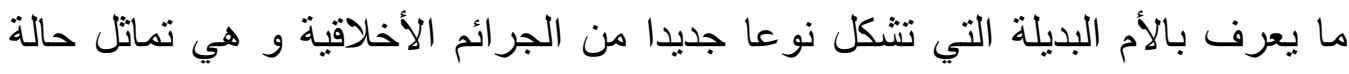

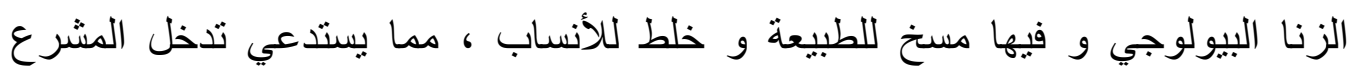
لتجريم هذه الظو اهر قبل ظهور ها ، خاصة وأن بنوك الأجنة و النطف أصبحت منتشرة

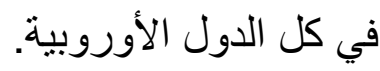


مجلة كلية الثريعة والقانون بتفهنا الأثراف ـ دقهلية العدد الثالث والعشرون لسنة اب ـ بم الجزء الأول

\section{قائمة المصادر و المراجع}

قائمة المصادر

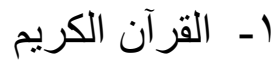

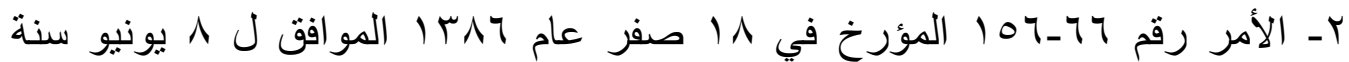
1977 المتضمن قانون العقوبات المعدل و المتمح

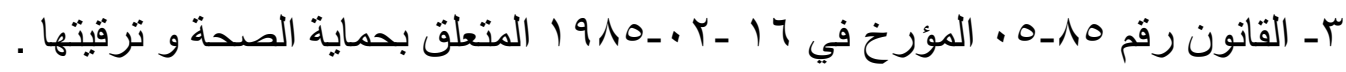

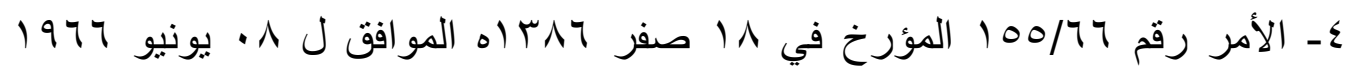

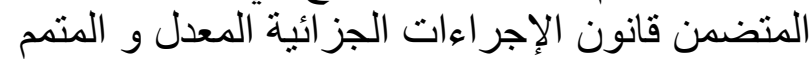

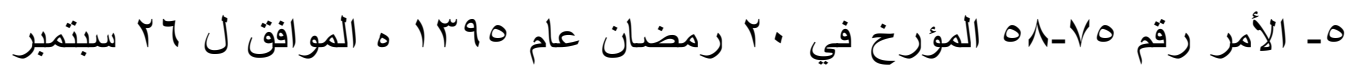

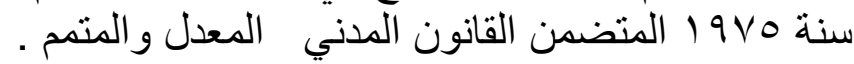

قائمة المراجع

الكتب

أحسن بوسقيعة. الوجيز في القانون الجزائي و الجرائم ضد الأموال ـ دار هومة ـ

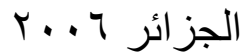

عبد العزيز سعد - الجرائم الواقعة على نظام الأسرة - الديوان الوطني للأشغال

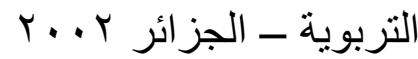

اسحاق ابراهيم منصور - الموجز في علم الاجرام و العقاب - ديوان المطبوعات

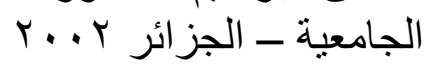

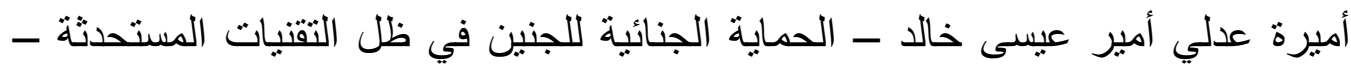

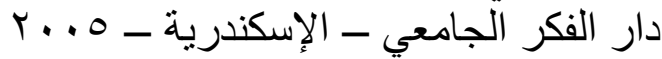

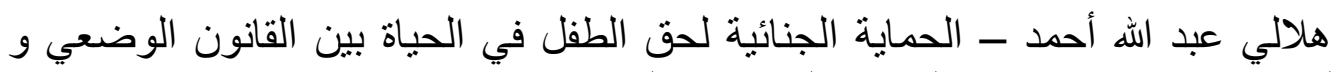

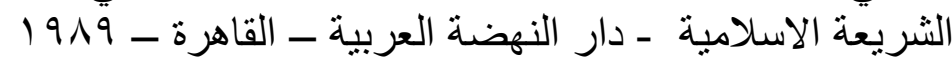

رضا عبد الحليم عبد المجيد ـ الحماية القانونية للجنين البشري ـ دار النهضة العربية

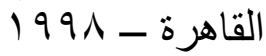

شوفي عبده الثـاهي - الفكر الاسلامي و القضايا الطبية المعاصرة - دار النهضة العربية - القاهرة المباهي 
عبد الحميد المنشاوي ـ الطب الثرعي ـ دار الكتاب الحديث ـ مصر سو 199 محمد صبحي نجم - شرح قانون العقوبات الجزائري - القسم الخاص - ديوبن

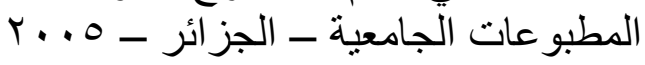
بن وارث محمد ـ مذكر ات في القانون الجزائي الجزائري ـ القسم الخاص ، دار هومة

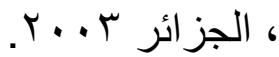

